\title{
EVALUATED NUCLEAR STRUCTURE DATA FILE
}

\author{
A Manual for Preparation of Data Sets
}

\author{
J.K. Tuli \\ DISCLAIMER
}

\begin{abstract}
This report was prepared as an account of work sponsored by an agency of the Uniter States Government. Neither the United States Government nor any agency thereof, nor any of their employees, makes any warraniy, express or implied, or assumes any legal liability or responsibility for the accuracy, completeness, or usefulness of any information, apparatus, produch, or process disclosed, or represents that its use would not infringe privately owned rights. Reference berein to any specific commercial product, process, or service by trade name, trademark. manufacturer, or otherwise does not necessarily constitute or imply its endorsement, recommendation, or favoring by the United States Government or any agency thereof. The views and opinions of autbors expresced kerein do not necessarily state or reflect those of the United States Government or any agency thereof.
\end{abstract}

March 1983

NOTIGE

PORTIOHS OF THIS REPORT ARE ULLEIBLE.

It has been reproduced from the best available copy to permit the broadest possible availability.

\section{NATIONAL NUCLEAR DATA CENTER}

\section{BROOKHAVEN NATIONAL LABORATORY ASSOCIATED UNIVERSITIES, INC.}

UNDER CONTRACT NO. DE-ACO2-76CHOOO16 WITH THE

UNITED STATES DEPARTMENT OF ENERGY 


\section{CONTENTS}

CHAPTERS

I.

INTRODUCTION

1

II.

GENERAL STRUCTURE OF THE DATA FILE

A. General Organization

2

B. Data Set Structure

C. File Storage and Transmittal

III.

STANDARD ONE-CARD RECORD FORMATS

A. Introduction 6

B. The Standard One-Card Record Formats 6

C. Summary

IV. RECORDS CONTAINING MORE THAN ONE CARD

A. Card Enumeration $\quad 17$

B. Formats for Continuation Cards 17

C. Allowed Data Types on Continuation Records 18

V.

DETAILED FIELD DESCRIPTIONS

20

\section{APPENDICES}

A.

SAMPLE DATA SET INPUT/OUTPUT

B.

ENSDF TRANSLATION DICTIONARY

C.

DATA EVALUATION CENTERS

D.

NUCLEAR DATA SHEETS POLICIES, CONVENTIONS

1. Conventions

2. Abbreviations and symbols

3. General Policies - Theory

4. Bases for spin and parity assignments

FIGURES

1.

ENSDF Organization Chart

Data Set Structure

3

2.

Formai Summary

5

3.

Formac summary 


\title{
EVALUATED NUCLEAR STRUCTURE DATA FILE*
}

\author{
A Manual for Preparation of Data Sets
}

\author{
J. K. Tuli
}

\section{INTRODUCTION}

\begin{abstract}
This manual ${ }^{1}$ describes the organization and structure of the Evaluated Nuclear Structure Data File (ENSDF). This computer-based file is maintained by the National Nuclear Data Center (NNDC) at Brookhaven National Laboratory for the international Nuclear Structure and Decay Data Network. ${ }^{2}$

For every mass number (presently, A $\leq 263$ ), the Evaluated Nuclear 3tructure Data File (ENSDF) contains evaluated structure information. For masses $A \geq 45$, this information is documented in the Nuclear Data Sheets; for A<45, ENSDF is based on compilations published in the journal Nuclear Physics. The information in ENSDF is updated by mass chains with a present cycle time of approximately six years.
\end{abstract}

The author gratefully acknowledges many suggestions and comments received during the preparation of this manual. Special thanks are due to M. J. Martin (ORNL), C. M. Lederer (U.C., Berkeley), R. L. Bunting (INEL), A. Lorenz (IAEA). D. E. Alburger (BNL) and the following colleagues at NNDC: S. Pearlstein, M. R. Bhat, T. W. Burrows, R. R. Kinsey. C. L. Dunford and B. J. Barton. P. Dixsn (NNDC) helped with the production of this report. This research was supported by the office of Basic Energy Sciences. U. S. Department of Energy.

\footnotetext{
-Designed by W. B. Ewbank at the Nuclear Data Project, Oak Ridge National Laboratory. ${ }^{1}$ This is a revision of the Nuclear Data Project. Dak Ridge National Laboratcry. report of the same name [ORNL-5054/R1 (February 1978)] by $W$. B. Ewbank and M. R. Schmorak.

${ }^{2}$ Coordinated by the International Atomic Energy Agency, Vienna - see Appendix C for list of evaluation centers.
} 


\section{GENERAL ORGANIZATION AND STRUCTURE OF THE DATA FILE}

\section{A. General Organization}

The Evaluated Nuclear Structure Data File (ENSDF) is made up of a collection of "data sets" which present one of the following kinds of information:

1. The evaluated results of a single experiment. e.g., a radioactive decay or a nuclear reaction.

2. The combined evaluated results of a number of experiments of the same kind, e.g., (Heavy ion, $x n \gamma$ ). Coulomb excitation, etc.

3. The adopted properties of the nucleus.

4. The references used in all the data sets for the given mass number. This data set is based upon reference codes (key numbers) used in various data sets for a given mass number and is addect to the file by NNDC.

5. The summary isformation for a mass chain giving information: e.g., evaluator's name and affiliations, cutoff date. Nuclear Data Sheets publication details, etc.

The data sets in ENSDF are organized by their mass number. Within a mass number the data sets are of two kinds:

i. Data sets which contain information pertaining to the complete mass chain. These data sets contain information of the type (4) and (5) given above.

ii. Data sets belonging to a given nucleus (Z-value).

Data sets (ii), i.e. for a given nucleus (Z-value), consist of the following:

a. Adopted data set (only one per Z-value) giving adopted properties of the levels and radiations seen in that nucleus.

b. Data sets giving information of the type (1) or (2) above.

If there is more than one data set of type (1) or (2) for a given nucleus, then an adopted data set is required for that nucleus. lf there is only one data set for a given nucleus, then that set is assumed also to present the adojted properties for that nucleus.

The general organization of ENSDF is shown schematically in Fig. 1. 


\section{Evaluated Nuclear Structure Data Flle \\ Organization Chart}

$\omega$

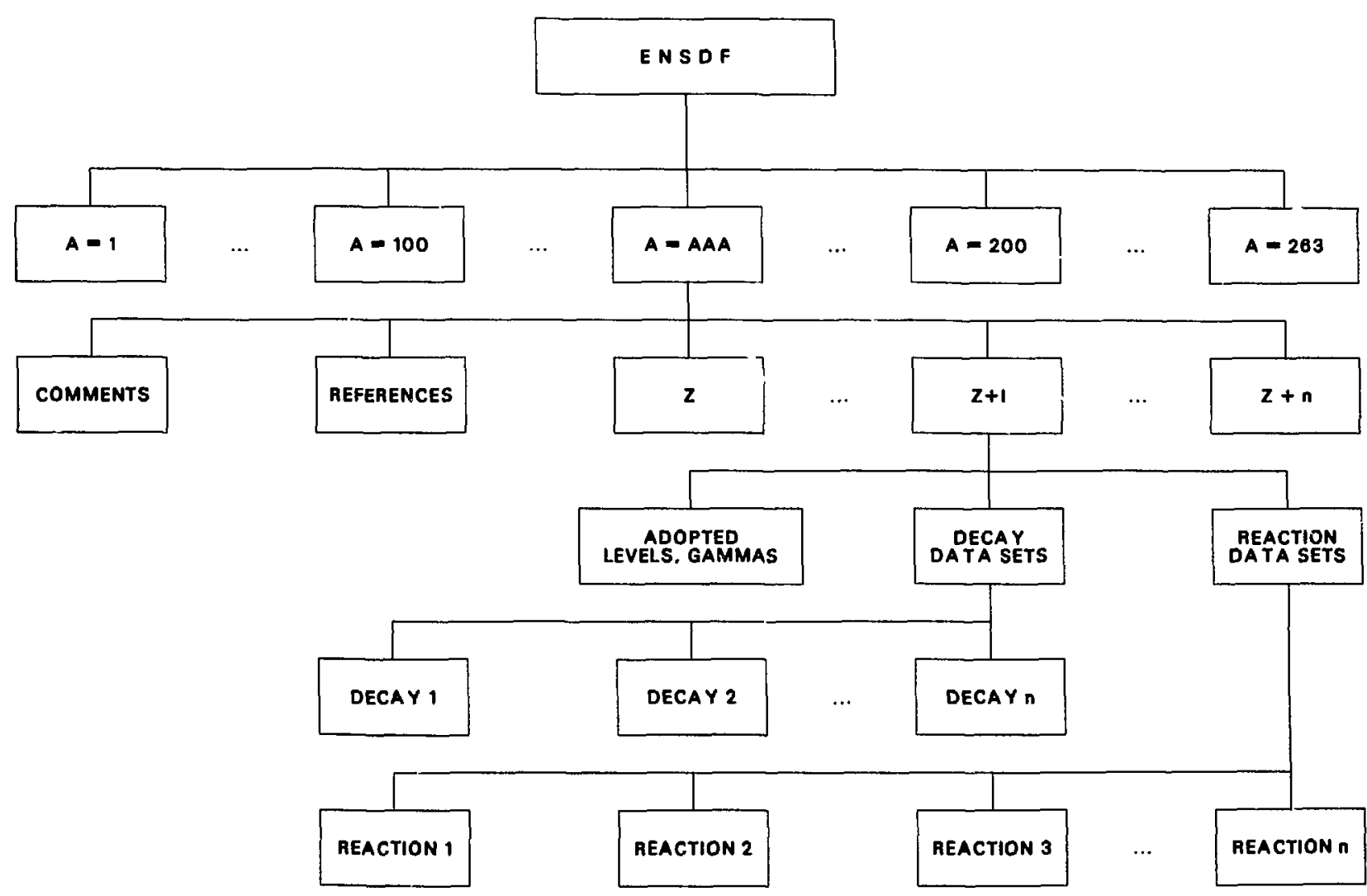

Fig. 1 


\section{General Organization}

\section{B. Data Set Structure}

A data set is composed of records; each record is made up of one or more card images. Data set structure is given in Fig. 2 and is described below:

A data set musi begin with an IDENTIFICATION record and must end with an END record (a blank card). Between these two records, there can be as many additionai records as are needed to describe fully the experimental or the evaluated data.

Immediately following the IDENTIFICATION record is a group of records which contain information about the entire data set (\#1 and \#2 in Fig. 2). The general COMMENT (C), NORMALIZATION (N). Q-VALUE (Q), and IARENT (P) records are of this type. Not all of these records are included in every data set.

The body of a data set (\#3 and \#4 in Fig. 2) is composed of numeric data records which describe the measured or deduced properties of levels, $\gamma$ rays, $\alpha$ particles, etc. These records are associated with the level which decays (for GAMMA records) or the level which is populated (for BETA. EC. or ALPHA records). Thus, each LEVEL record is followed by a group of records describing charged-particle decay into the level and $\gamma$-ray decay out of the level $(\# 4$ in Fig. 2).

If a GAMMA record (or ALPHA, or EC, or BETA) properly belongs in a data set but cannot be associated with any particular level, then the record should be placed in the data set before any LEVEL records (\#3 in Fig. 2).

The placement of COMMENT records is described in Chapter III.

\section{File Storage and Transmittal}

The data sets sent to NNDC for inclusion in ENSDF can be in any order, as the file is stored in a random access mode (by data sets) using a data base management system. Copies of the file are transmitted in the form of a sequential file on magnetic tape. The data sets in the sequential file are arranged by mass numbers in increasing numerical order. For a given mass number the data sets are organized as given in Fig. 1, ordering them from left to right. Decay data sets are placed under the daughter nucleus and are ordered by $A$, $Z$ and then the excitation energy of the parent nucleus. The reaction data sets are given under the residual nucleus and are ordered by the $A$, $Z$ of the target nucleus follwed by the $A, Z$ of the incident particle and then by the energy of the incident particle. 
II. General Organization

\section{Data Set Structure}

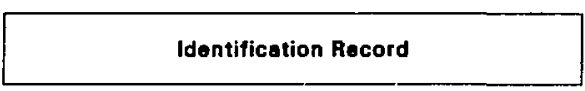

2

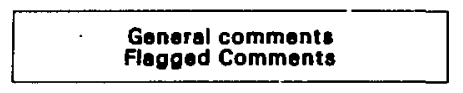

3

\begin{tabular}{|c|}
\hline $\begin{array}{c}\text { Q Record } \\
\text { Comment on O Record }\end{array}$ \\
\hline $\begin{array}{c}\text { Parent Record } \\
\text { Comment on P Record }\end{array}$ \\
\hline $\begin{array}{c}\text { Normalization Record } \\
\text { Commont on Normalization }\end{array}$ \\
\hline
\end{tabular}

3

Unplaced Radiations

(G,B,A,E, otc.)

4

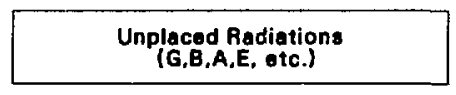

Level Record

Rediation records

\begin{tabular}{|c|}
\hline $\begin{array}{c}\text { Level Record } \\
\text { Radiation records }\end{array}$ \\
\hline$\cdot$ \\
$\cdot$ \\
\hline $\begin{array}{c}\text { Level Record } \\
\text { Radiation Records }\end{array}$ \\
\hline
\end{tabular}

End Record

Fig. 2 


\section{II. STANDARD ONE-CARD RECORD FORMATS}

\section{A. Introduction}

In most cases, all information for a record can be placed on a single $60-$ column card. A "standard" format has been defined for each one-card record, such that the most cornmonly used quantities can be placed on a single card. The standard formats are described in this section for each record. If a needed quantity is not iricluded in the standard format or if a value will not fit within the field defined for the value by the standard format, or if a record cannot be contained on a single card, then additional cards can be prepared as described in Chapter IV (for examples, see Appendix A). Note that many of the analysis programs, at present, do not process standard fields when placed on the continuation cards.

\section{B. The Standard One-Card Record Formats}

Record formats are given below in the same order in which they would normally be encountered in a data set. Conditions under which each record may appear or be required are given in parentheses. The format descriptions give the fields (in inclusive card-column numbers), the field names (the formal "name" of the quantity that goes into the field), and a brief field description. Card columns not explicitly included in the fields are expected to be blank. A detailed description of each field can be found in the reference section noted. (Any numerical field left blank usually implies that the numerical information is lacking. Numbers will usually be assumed to be positive unless stated otherwise.) Numbers can be entered anywhere in the appropriate field (i.e., there is no need to left-adjust or right-adjust.) 
III. Standard One-Card Record Formats

\section{THE IDENTIFICATION RECORD}

(Required for all data sets. Must precede all other records.)

Field (Col.)

$$
1-5
$$

$6-9$

10-39

$40-64$

$65-74$

$75-80$

Name
NUCID
DSID
DSREF
PUB
DATE

Description

Nucleus Identification

Must be blank

Data set identification

References to main supporting publications and analyses

Publication Information

The date (year/month/day) when the data set was placed in BNSDF (entered automatically by computer)
Reference

V.A

V.B

V.C

V.D

V.E

\section{THE COMMENT RECORD}

\section{i. General Comments}

Field (Col.)

$$
1-5
$$

6

7

8-9

$10-80$
Name Description

NUCID Nucleus identification

Blank or 1.

Any other character, e.g., $2,3, \ldots, 9, A, B, \ldots, Z$, etc., for continuation records

C

Letter " $C$ ", " $D$ ", or "T" is required

See notes 2 and 3 below

Must be blank

C'TEXT Text of the comment.

[See ENSDF Translation Dictionary

(Appendix B)]
Reference

V.A

V.G

NOTES:

1. The comment refers to the whole data set. In the case that NUCID contains only the mass number, $A$, the comment refers to the whole mass-chain A. General comments must be placed in a data set before any $L, G$, $B, E$, or A records.

2. Letter " $\mathrm{T}$ " in place of " $\mathrm{C}$ " in col. 7 of a comment record indicates to the output programs that this record should be reproduced "as is" and the blanks in the record should not be squeezed out. See example in Appendix $A$.

3. Letter " $D$ " in place of " $C$ " in col. 7 of a comment record indicates to the output programs that this is a documentation record and should be ignored. This record will also be ignored by the various analysis programs. 


\section{THE COMMENT RECORD (cont.)}

\section{ii. Record Comments and Flagged Comments}

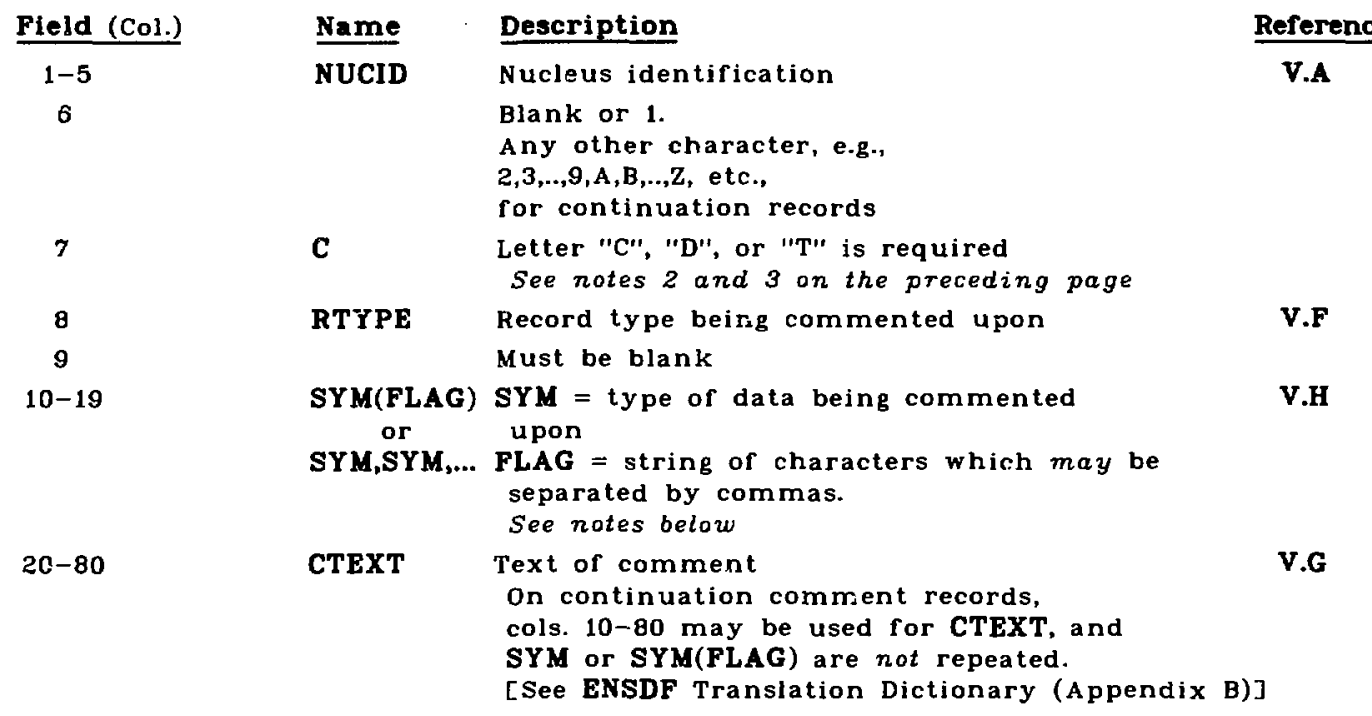

NOTES:

1. Record comment placed at the head of the data set -This refers to all records of the specified RTYPE in the data set. -The comment will normally appear only in the table for that RTYPE in the output. For example, if the comment is on levels (" $L$ " in col. 8) it will appear only in the level properties table.

-The comment with SYM only (no FLAG) in cols. 10-19 will appear as a footnote on the column heading corresponding to the data type specified by SYM.

- When the FLAG is also specified then only those data values of data types specified by $3 Y M$ in the records which have one of the characters specified in FLAG in their col. 77 will get foot-noted. See examples in Appendix A.

2. Flagged comments must be placed before any L, G, B, E or A records.

3. Record comments placed immediately following a record refer only to that one record. (For example, a comment with " $L$ " in col. 8 and " $T$ " in col. 10, placed at the head of a data set, refers to all level half-lives in that, data set. The same comment placed immediately following the level record for the second-exited state refers only to the half-life of the second-excited state.)

4. Comments for which RTYPE is $N$, $P$, or $Q$ must be placed immediately following those records. 
1II. Standard One-Card Record Formats

\section{THE NORMALIZATION RECORD}

(Hust precede L. G. B, E, A records.

Required if an absolute normalization is possible, used mainly with deccy and $(n, \gamma)$ reaction data sets.)

\begin{tabular}{c} 
Field (Col.) \\
\hline $1-5$ \\
6 \\
7 \\
8 \\
9 \\
$10-19$
\end{tabular}

$20-21$

$22-29$

$30-31$

$32-39$

$40-41$

$42-49$

$50-55$

$56-80$
DNR

NT

Name
NUCID
N
NR

\section{Description}

Nucleus (Daughter/Product) identification

Blank or 1

Must be blank

Letter "N" is required

Must be blank

Multiplier for converting relative photon intensity ( $R I$ in the GAMMA record) to photons per 100 decays of the parent through the decay branch or to photons per 100 neutron captures in an $(n, \gamma)$ reaction. Required if the absolute photon intensity can be calculated.

Standard uncertainty in NR

Multiplier for converting relative transition intensity (including conversion electrons) [TI in the GAMMA record] to transitions per 100 decays of the parent through this decay branch or per 100 neutron captures in an $(n, \gamma)$ reaction.

Required if TI are given in the GAMMA record and the normalization is known.

DNT

BR

DBR

NB

DNB

NB

standard uncertainty in NT

Branching ratio multiplier for converting intensity per 100 decays through this decay branch to intensity per 100 decays of the parent nucleus.

Required if known.

Standard uncertainty in BR V.K

Multiplier for converting relative $\beta^{-}$and $\epsilon$ intensities (IB in the $B$ - record; IB, IE, $T I$ in the $E C$ record) to intensities per 100 decays through this decay branch. Required if known.

standard uncertainty in NB V.K

Must be blank
V.K

V.K

V.K
V.I

Reference

V.A

V.I

V.I 


\section{THE PARENT RECORD \\ (Reguired for all decay data sets, except IT and SF decay. Must precede $L, G, B, E, A$ records.)}

\begin{tabular}{|c|c|}
\hline Field (Col.) & Name \\
\hline $1-5$ & NUCID \\
\hline 6 & \\
\hline 7 & \\
\hline 8 & $P$ \\
\hline 9 & \\
\hline $10-19$ & $\mathbf{E}$ \\
\hline $20-21$ & DE \\
\hline $22-39$ & $\mathbf{J}$ \\
\hline $40-49$ & $T$ \\
\hline $50-55$ & DT \\
\hline $56-64$ & \\
\hline $65-74$ & $\mathbf{Q P}$ \\
\hline $75-76$ & DQP \\
\hline $77-80$ & \\
\hline
\end{tabular}

\section{Description}

Parent Nucleus identification

Reference

Blank or 1

Must be blank

Letter " $P$ " is required

Must be blank

Energy of the decaying level in $\mathrm{keV}$

V.R

(0 ror g.s.)

V.A

standard uncertainty in $\mathbf{E}$

V.K

Spin and parity

V.T

Half-life; units must be given

V.N

standard uncertainty in $\mathbf{T}$

V.L

Must be blank

Ground-state $Q$-value in keV (total energy

V.I

available for g.s. - g.s. transition); will always be a positive number

Standard uncertairty in QP

V.K

\section{THE Q-VALUE RECCRD}

(Reg-red for Adopted Levels and Adopted Levels. Gammas data sets. Must precede $L, G, B, E, A$ records.

If signs are not given, they will be assumed to be +.)

\begin{tabular}{|c|c|}
\hline Field (Col.) & Name \\
\hline $1-5$ & NUCID \\
\hline $\begin{array}{l}6 \\
7\end{array}$ & \\
\hline 8 & $\mathbf{Q}$ \\
\hline 9 & \\
\hline $10-19$ & $Q^{-}$ \\
\hline $20-21$ & $\mathrm{DQ}^{-}$ \\
\hline $22-29$ & SN \\
\hline $30-31$ & DSN \\
\hline $32-39$ & $\mathbf{S P}$ \\
\hline $40-41$ & DSP \\
\hline $42-49$ & $\mathbf{Q A}$ \\
\hline $50-55$ & DQA \\
\hline $56-80$ & QREF \\
\hline
\end{tabular}

\section{Description}

Nucleus identification

Blank or 1

Must be blank

Letter " $Q$ " is required

Must be blank

Total energy (kev) available for $\beta^{-}$decay

of the ground state. $\left(Q^{-}>0\right.$ if $\beta^{-}$

decay is energetically possible.

$Q^{-}<0$ represents the $Q_{\varepsilon}$ energy of

the $Z+1$ ( $Z$ = proton number) isobar.)

Standard uncertainty in $Q^{-}$

Neutron separation energy in keV

Standard uncertainty in SN

Proton separation energy in keV

Standard uncertainty in SP

Total energy (kev) available for $\alpha$ decay

of the ground state

Standard uncertainty in $\mathbf{Q A}$

Reference citation(s) for the Q-values
V.K

Reference

V.A

V.J

V.J

V.K

V.J

V.K

V.J

V.K

v.c 


\section{THE LEVEL RECORD}

(Optional, although a data set usually has at least one.)

\begin{tabular}{|c|c|c|}
\hline Field (Col.) & Name & Description \\
\hline $1-5$ & NUC1D & Nucleus identification \\
\hline 6 & & $\begin{array}{l}\text { Blank or } 1 \\
\text { Any other character, e.g., } \\
2,3, . ., 9, A, B, . ., Z \text {, etc., } \\
\text { for continuation records }\end{array}$ \\
\hline 7 & & Must be blank \\
\hline 8 & I. & Letter " $L$ " is required \\
\hline 9 & & Must be blank \\
\hline $10-19$ & $\mathbf{E}$ & Level energy in keV \\
\hline $20-21$ & DE & Standard uncertainty in $B$ \\
\hline $22-39$ & $\mathbf{J}$ & Spin and parity \\
\hline $40-49$ & $\mathbf{T}$ & $\begin{array}{l}\text { Half-life of the level; units must be given. } \\
\text { Mean-life expressed as the width of a level. } \\
\text { in units of energy, may also be used }\end{array}$ \\
\hline $50-55$ & DT & Standard uncertainty in $T$ \\
\hline $56-64$ & $\mathbf{L}$ & $\begin{array}{l}\text { Angular momentum transfer in the reaction } \\
\text { determining he data set. (Whether it } \\
\text { is } L_{n}, L_{p} \text {, } \Delta L \text {, etc., is determined from } \\
\text { the DSID field of the IDENTIFICATION } \\
\text { record.) }\end{array}$ \\
\hline $65-74$ & $\mathbf{S}$ & $\begin{array}{l}\text { Spectroscopic strength for this level as deter- } \\
\text { mined from the reaction in the IDENTI- } \\
\text { FICATION record. (Spectroscopic ractor for } \\
\text { particle-exchange reactions; } \beta \text { for inelastic } \\
\text { scattering.) }\end{array}$ \\
\hline $75-76$ & $\mathbf{D S}$ & Standard uncertainty in $\mathbf{S}$ \\
\hline 77 & $\mathbf{C}$ & $\begin{array}{l}\text { Comment PLAG used } \\
\text { to refer to a particular comment record }\end{array}$ \\
\hline $78-79$ & MS & $\begin{array}{l}\text { Metastable state is denoted by "M " or } \\
\text { "M1" for the first (lowest energy) isomer; } \\
\text { "M2", for the second isomer, etc. }\end{array}$ \\
\hline 80 & $\mathbf{Q}$ & $\begin{array}{l}\text { The character "?" denotes an uncertain or } \\
\text { questionable level } \\
\text { Letter ' } S \text { " denotes neutron or proton } \\
\text { separation energy }\end{array}$ \\
\hline
\end{tabular}

\section{Reference}

V.A

V.R

V.X

V.T

V.N

V.L

V.V

V.U

V. $\boldsymbol{X}$

V.H

V.Q 
III. Standard One-Card Record Formats

\section{THE GAMMA RECORD}

(Must follow the LEVEL record for the level from which the $\gamma$ ray decays. Records for $\gamma$ rays which are unassigned in a level scheme should precede

the first level of the data set.)

\begin{tabular}{|c|c|}
\hline Field (Col.) & Name \\
\hline $1-5$ & NUCI \\
\hline 6 & \\
\hline 7 & \\
\hline 8 & G \\
\hline 9 & \\
\hline $10-19$ & $\boldsymbol{E}$ \\
\hline $20-21$ & DE \\
\hline $22-29$ & $\mathbf{R I}$ \\
\hline $30-31$ & DRI \\
\hline $32-41$ & $\mathbf{M}$ \\
\hline $42-49$ & $\mathbf{M R}$ \\
\hline $50-55$ & DMR \\
\hline $56-62$ & $\mathrm{CC}$ \\
\hline $63-64$ & DCC \\
\hline $65-74$ & TI \\
\hline $75-76$ & DTI \\
\hline 77 & C \\
\hline 78 & ORG \\
\hline 79 & END \\
\hline 80 & $\mathbf{Q}$ \\
\hline
\end{tabular}

\section{Description}

Nucleus identification

Blank or 1

Any other character, e.g., $2,3, \ldots, 9, \mathrm{~A}, \mathrm{~B}, . ., \mathrm{Z}$, etc.,

for continuation records

Must be blank

Letter " $G$ " is required

Must be blank

Energy of the $\gamma$-ray photon in keV

V.R

Standard $u$ irtainty in $E$

Relative pho $n$ inlensity ${ }^{\dagger}$

standard uncertainty in RI

Multipolarity of transition

Mixing ratio. $\delta$. (Sign must be shown

explicitly if known. If no sign is given.

it will be assumed to be unknown.)

Standard uncertainty in MR

V.L

Total conversion coefficient

V.I

standard uncertainty in CC

V.K

V.M

Relalive total transition intensity $\dagger$

V.K

V.H

Comment FLAG used to refer to

a particular comment rosord. The character * denotes a mu!tiply placed $\gamma$ ray

Letter " $C$ " denotes coincidence with a pre-

V.o

ceding radiation

Letter " $\mathrm{C}$ " denotes coincidence with a following radiation

The charncter "?" denotes an uncertain placement of the transition in the level scheme

Letter " $S$ " denotes an expected, but as yet unobserved, transition

tThe intensity units are defined by the NORMALIZATION record. 
III. Standard One-Card Record Formats

\section{THE BETA $\left(\beta^{-}\right)$RECORD}

(Nust follow the LEVEL record for the level which is fed by the $\beta^{-}$.)

\begin{tabular}{|c|c|}
\hline Field (Col.) & Name \\
\hline $1-5$ & NUCID \\
\hline 6 & \\
\hline 7 & \\
\hline 8 & $\mathbf{B}$ \\
\hline $\mathbf{9}$ & \\
\hline $10-19$ & $\mathbf{E}$ \\
\hline $20-21$ & DE \\
\hline $22-29$ & IB \\
\hline $30-31$ & DIB \\
\hline $42-49$ & LOGFT \\
\hline $50-55$ & DPT \\
\hline \multicolumn{2}{|l|}{$56-76$} \\
\hline $7 z$ & $\mathbf{C}$ \\
\hline $78-79$ & $\mathbf{U N}$ \\
\hline 80 & $\mathbf{Q}$ \\
\hline
\end{tabular}

Description

Nucleus identification

Blank or 1

Any other character, e.e.,

$2,3, \ldots, 9, A, B, \ldots, Z$, etc.

for continuation records

Must be blank

Letter " $B$ " is required

Must be blank

Endpoint energy of the $\beta^{-}$in keV

Given only if measured

standard uncertainty in $E$

Intensity of the $\beta^{-}$decay branch'

Standard uncertainty in IB

The log $f t$ for the $\beta^{-}$transition

for uniqueness given in col. 78-79

Standard uncertainty in LOGFT

Must be blank

Comment FLAG (Letter "C" denotes coincidence with a following radiation.)

Uniqueness classification for the $\beta^{-}$decay, e.g., "1U", "2U". (A blank signifies an allowed or a nonunique forbidden transition.)

The character "?" denotes an uncertain or questionable $\beta^{-}$decay

Letter " $S$ " denotes an expected or predicted transition
Reference

V.A

V.R

V.K

V.M

V.K

V.I

V.L

V.H

V.P

The intensity units are defined by the NORMALIZATION record. 


\section{THE EC (or EC $+\beta^{+}$) RECORD}

(Nust follow the LEVEL record for the level being populated in the decay.)

\begin{tabular}{|c|c|c|c|}
\hline Field (Col.) & Name & Description & Refere \\
\hline $1-5$ & NUCID & Nucleus identification & V.A \\
\hline 6 & & $\begin{array}{l}\text { Blank or } 1 \\
\text { Any oiher character, e.g., } \\
2,3, \ldots, 9, A, B, \ldots, Z \text {, etc., } \\
\text { ror continuation records }\end{array}$ & \\
\hline 7 & & Must be blank & \\
\hline 8 & $\mathbf{E}$ & Letter " $E$ " is required & \\
\hline 9 & & Must be blank & \\
\hline $10-19$ & $\mathbf{E}$ & $\begin{array}{l}\text { Energy for electron capture to the level } \\
\text { Given only if measured }\end{array}$ & V.R \\
\hline $20-21$ & DE & Standard uncertainty in $E$ & V.K \\
\hline $22-29$ & IB & Intensity of $\beta^{+}$-decay branch ${ }^{\dagger}$ & V.M \\
\hline $30-31$ & DIB & Standard uncertainty in IB & V.K \\
\hline $32-39$ & IE & Intensity of electron capture brancht & $\mathbf{V . M}$ \\
\hline $40-41$ & DIE & Standard uncertainty in IE & V.K \\
\hline $42-49$ & LOGFT & $\begin{array}{l}\text { The log } f t \text { for }\left(\epsilon+\beta^{+}\right) \text {transition } \\
\text { for uniqueness given in col. } 78-79\end{array}$ & V.I \\
\hline $50-55$ & DFT & Standard uncertainty in LOGFT & V.L \\
\hline $65-74$ & TI & Total $\left(\epsilon+\beta^{+}\right)$decay intensity! & V.M \\
\hline $75-76$ & DT1 & Standard uncertainty in $\mathbf{T I}$ & V.K \\
\hline 77 & $\mathbf{c}$ & $\begin{array}{l}\text { Comment FLAG (Letter "C" denotes } \\
\text { coincidence with a following radiation.) }\end{array}$ & V.H \\
\hline $78-79$ & UN & $\begin{array}{l}\text { Uniqueness classification for } \epsilon \text {, } \beta^{+} \text {decay. } \\
\text { e.g., "1U", " } 2 U^{\prime} \text {. (A blank signifies an } \\
\text { allowed or a nonunique forbidden tran- } \\
\text { sition.) }\end{array}$ & V.P \\
\hline 80 & $\mathbf{Q}$ & $\begin{array}{l}\text { The character "?" denotes an uncertain or } \\
\text { questionable } \epsilon \text {, } \beta^{+} \text {branch } \\
\text { Letter "S" denotes an expected or predicted } \\
\text { transition }\end{array}$ & \\
\hline
\end{tabular}

IE, IB and TI must be in the same units (see also NB in NORMALIZATION record). 
1II. Standard Ore-Card Record Formats

\section{THE ALPHA RECORD}

\begin{tabular}{|c|c|c|c|}
\hline Field (Col.) & Name & Description & Reference \\
\hline $1-5$ & NUCID & Nucleus identification & V.A \\
\hline $\begin{array}{l}6 \\
7\end{array}$ & & $\begin{array}{l}\text { Blank or } 1 \\
\text { Must be blank }\end{array}$ & \\
\hline 8 & $\boldsymbol{A}$ & Letler " $A$ " is required & \\
\hline 9 & & Must be blank & \\
\hline $10-19$ & $\mathbf{E}$ & Alpha energy in $\mathrm{keV}$ & V.R \\
\hline $20-21$ & DE & Standard uncertainty in $E$ & V.K \\
\hline $22-29$ & IA & $\begin{array}{l}\text { Intensity of a-decay branch in percent of } \\
\text { the total a decay }\end{array}$ & $\mathbf{V} . \mathbf{M}$ \\
\hline $30-31$ & DIA & Standard uncertainty in IA & V.K \\
\hline $32-39$ & $\mathbf{H F}$ & Hindrance factor for $\alpha$ decay & V.1 \\
\hline $40-41$ & DHF & Standard uncertainty in $\mathbf{H F}$ & V.L \\
\hline $42-76$ & & Must be blank & \\
\hline 77 & c & $\begin{array}{l}\text { Comment FLAG (Letter "C" denotes } \\
\text { coincidence with a following radiation.) }\end{array}$ & V.H \\
\hline $\begin{array}{c}78-79 \\
80\end{array}$ & $Q$ & $\begin{array}{l}\text { Must be blank } \\
\text { The character "?" denotes uncertain or } \\
\text { q:iestionable a branch } \\
\text { Letter "S" denotes an expected or pre- } \\
\text { dicted a branch }\end{array}$ & \\
\hline
\end{tabular}

\section{THE REFERENCE RECORD}

(Record can occur only in Reference data set.

NNDC provides the Reference data set)

\begin{tabular}{c} 
Field \\
\hline $1-3$ \\
$4-7$ \\
6 \\
9 \\
$10-15$ \\
$16-80$
\end{tabular}

Name Description

Reference

MASS Mass Number

Must be blank

$R \quad$ Letter " $R$ " is required

Must be blank

KEYNUM Reference key number

V.C

REFERENCE Abbreviated reference (from NSR file)

12. THE END RECORD

(Required for all data sets. Must be the last record in a data set.)

\section{Field (Col.)}

$$
1-80
$$

\section{Description}

All columns are blank

\section{Summary}

The following figure (Fig. 3) summarizes the standard one-card formats for all allowed record types. 
SUMMARY

ENSDF STANDARD ONE - CARD FORMATS

RECORD TYPE

IDENTIF ICATION

GENERAL COMMENT

FLAGGED COMMENT

NORMALIZATION

PARENT

Q-VALUe

LEVEL

GAMMA

$\vec{a}$

BETA

EC

ALPHA

REFERENCE

END

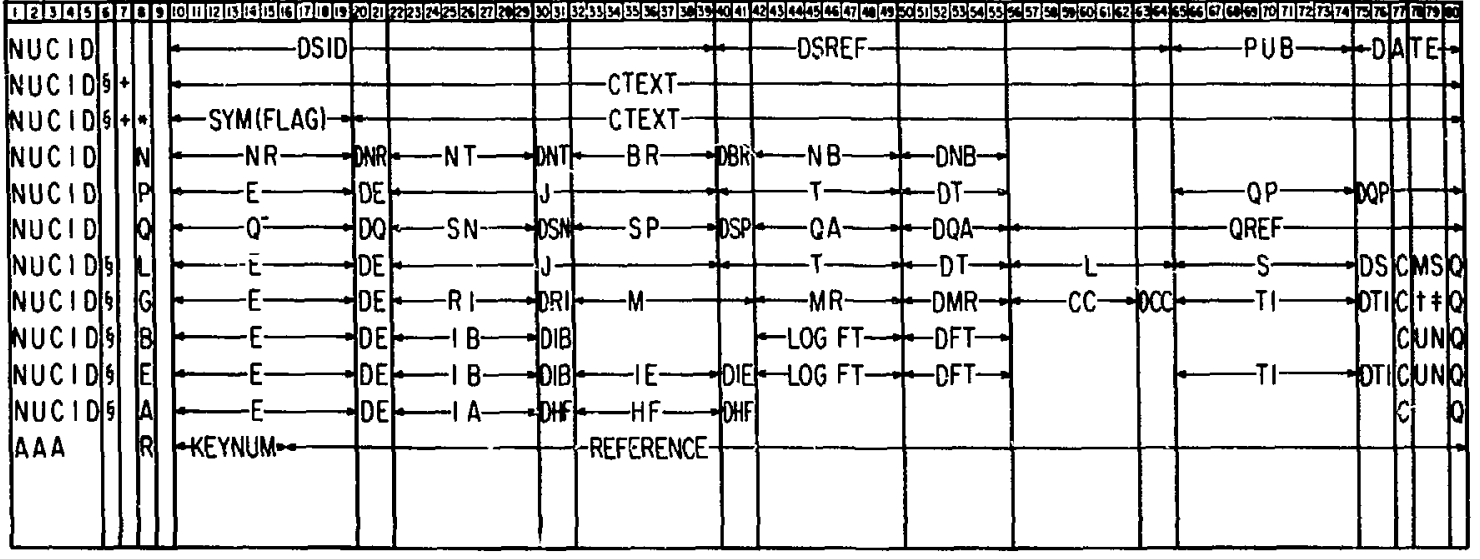

- = RTYPE

$\$=$ COLUMN 6 IS BLANK OR I FOR THE FIRST CARD RECORD, ANY OTHER CHARACTER FOR CONTINUATION

$t=$ ORG

$\neq=$ END

$+=$ "C" OR "D" OR "T"

$A A A=$ MASS NUMBER

Fig. 3 


\section{RECORDS CONTAINING MORE THAN ONE CARD}

\section{A. Card Enumeration}

If all the information for a given record type cannot be contained on a single card, it is possible to use additional cards to describe the record fully. The first card of a record will have a blank or number 1 in col. 6 . Subsequent cards will have characters different from blank or 1 (usually running numbers: 2 to 9 or letters $A$ to $Z$ ). The continuation cards are allowed only for LEVEL, GAMMA, B-, and EC records,

\section{B. Format for Continuation Cards}

\section{THE CONTINUATION RECORD}

(Nust follow the record of the same RTYPE.)

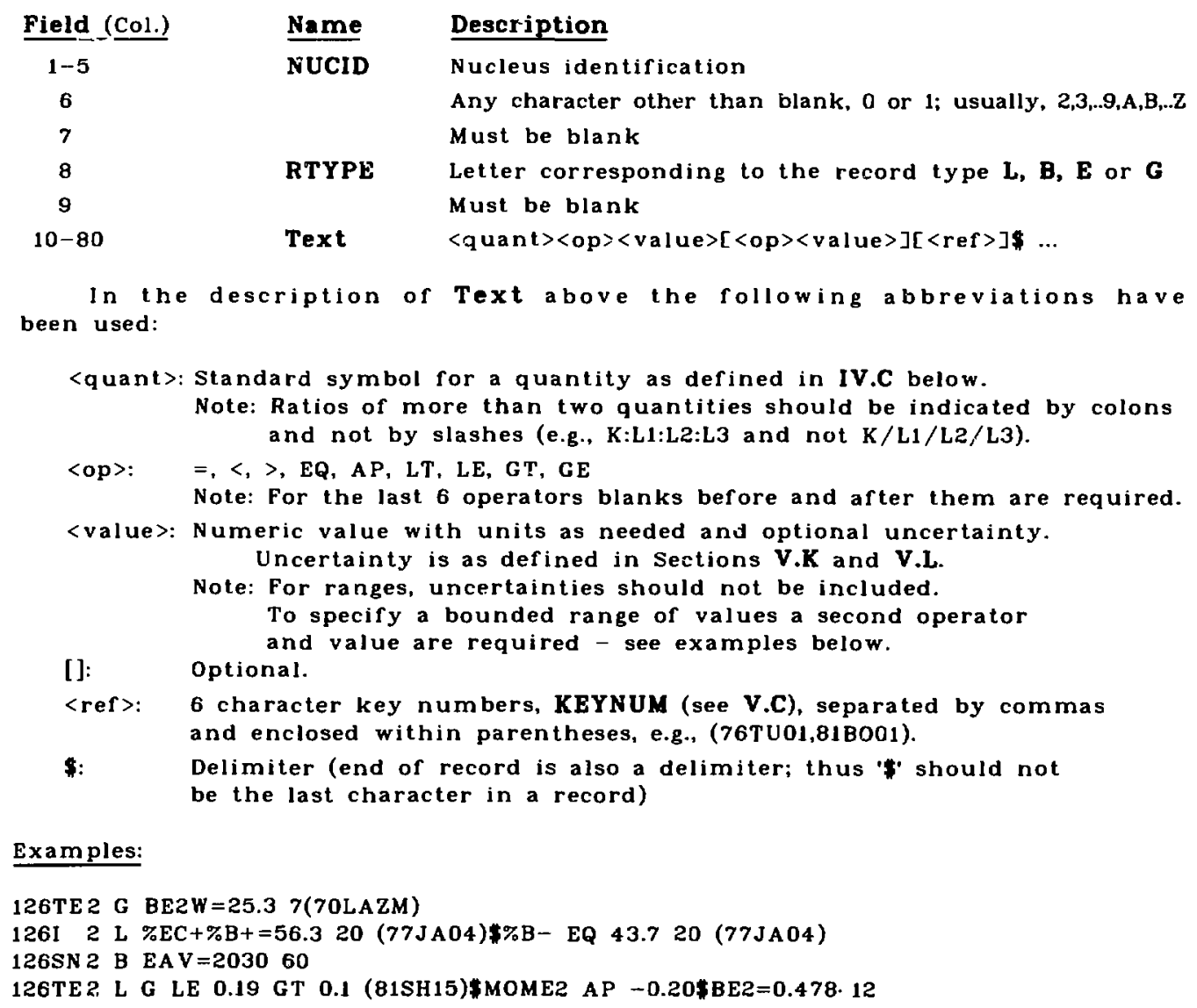




\title{
C. ALLOWED DATA TYPES ON CONTINUATION RECORDS
}

\begin{abstract}
Each record type is permitted to contain only a limited (but extendable) set of data types. For example, a GAMMA record is not allowed to contain information of data type DTYPE = J (nuclear spin). Neitier may a LEVEL record contain LOGFT information. For each record type, the following table lists the data type permitted as of March 1983.
\end{abstract}

\section{The PARENT Record}

Al! allowed data types are included in the standard format description in Section III.B.4

\section{The Q-VALUE Record} in Section III.B.5

\section{The LEVEL Record}

Allowed data types E, DE, J, T, DT, L, S. DS, C, MS, Q. are described with the standard formats in Section III.B.6. Additional allowed data types are:

\section{TYPE}

\%EC, \%B+, \%EC+\%B+, \%B-, \%IT, \%SF, \%A, \%P, \%N

G

MOME1, MOME2, ,.. MOMM1, MOMM2, ... CONF

BE1, BE2, ...

ISPIN
Description

Peicent decay of the level by $\varepsilon, \beta^{+}, \varepsilon+\beta^{+}$. $\beta^{-}$, isomeric transition, spontaneous fission, $\alpha$, proton, or neutron decay.

g-factor of the level

Electric moments: dipole, quadrupole, ...

Magnetic moments: dipole, quadrupole. ...

Nuclear configuration of the level

Reduced electric transition probability (upward) given in units $\mathrm{e}^{2} \times(\text { barns })^{\mathrm{L}}$, where $\mathrm{l}=1,2, \ldots$ for the trar sition from the ground state to this level Isobaric spin

\section{The GAMMA Record}

Allowed data types, E, DE, RI, DRI, M, MR, DMR, CC, DCC, TI, DTI,

C, ORG, END, Q, are described with the standard formats in

Section III.B.7. Additional allowed data types are;

DTYPE

BE1, BE2. ...

BE1W, BE2W, $\ldots$

BM1, BM2, $\ldots$

\section{Description}

Reduced electric transition probability (downward) given in units of $e^{2} \times$ (barns) ${ }^{L}$. where $\mathrm{L}=1,2, \ldots$

Reduced electric transition probability (downward) given in single-particle (Weisskopf) units

Reduced magnetic transition probability (downward) given in units of $\mu^{2}{ }_{N} \times$ (barns) $^{L-1}$. where $L=1,2, \ldots$ 
IV. Continuation Records

DTYPE

BM1W, BM2W, ...

CEK, CEL, CEL1, $\ldots$

KC, LC, LIC, ...

EKC, ELC, ELIC, $\ldots$

$\mathrm{K} / \mathrm{L}, \mathrm{M} / \mathrm{L}, \mathrm{L} 1 / \mathrm{L} 2, \ldots$

$\mathrm{K} / \mathrm{T}, \mathrm{L} / \mathrm{T}, \quad \ldots$

\section{GAMMA Record (continued)}

Description

Reduced magnetic transition probability

(downward) given in single-particle (Weisskopf) units

Conversion-electron (ce) intensity for K. L. $\mathrm{L}_{1}$. ... conversion

Theoretical $\mathrm{K}-, \mathrm{L}-, \mathrm{L}_{1}-\ldots$ conversion coefficient Measured $K-, L-, L_{1}-\ldots$ conversion coefficient Conversion-electron intensity ratios

Ratio of K, L, ... ce-intensity to total $(\gamma+c e)$ intensity

\section{The BETA $\left(B^{-}\right)$Record}

Allowed daia types E, DE, IB, DIB, LCGFT, DFT, COIN, UN, Q, are described with the standard formats in Section III.B.8. Additional allowed dala types are:

DTYPE

EAV

\section{Description}

Average energy of the $\beta^{-}$spectrum

\section{The EC Record}

Allowed data types, E, DE, IB, DIB, IE, DIE, LOGFT, DFT, TI, DTI, C, UN, $Q$, are described with the standard formats in Section III.B.9. Additional allowed data types are:

\section{DTYPE}

EAV

CK, CL, CM, CN+

\section{Description}

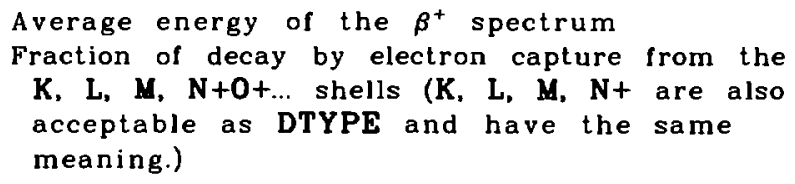

\section{The ALPHA Record}

All allowed data types are included in the standard format description in Section III.B.10. 


\section{DETAILED FIELD DESCRIPTIONS}

\section{A. NUCID}

The standard nucleus identification consists of two parts - mass number in cols. (1-3), right justified and element name (or $\mathrm{Z}-100$ for $\mathrm{Z}>103$ ) in (col. 4-5). left justified. The nucleus identification must be contained within the field defined for it (cols. 1-5). The nucleus identification must be included on every IDENTIFICATION record. It must also be included on every card of a data set except the END record. Comments and reference data sets pertaining to the whole A-(mass) chain evaluation contain only the A-value in the NUCID field.

\section{B. DSID}

The Data Set ID for an ENSDF data set must serve as a unique, computer recognizable identification for the data set. For that purpose, the following rules should be strictly observed for ENSDF entries. Single blanks have meaning and should be used according to the formats below. A colon may be used to define a sub-topic. All characters must be confined to the 30 spaces allowed. Optional fields are given in italics. General categories are given in upper and lower cases and further defined.

\section{GENERAL ID'S}

REFERENCES

COMMENTS

ADOPTED LEVELS

ADOPTED LEVELS, GAMMAS

DECAY DATA SET ID'S

Parent Mode Decay (Half-life units)

Parent should be the parent isotope symbol (e.g.) 52CR.

Mode may be one of B+, B-. EC, IT, A, or SF.

Half-life can be of the form NUM defined in V.I.

Units are required if Half-life is given. Units can be one of the following:

Y, D, M, S, MS, US, NS, PS, FS, AS, EV, KEV, or MEV (See also V.N)

MUONIC ATOM

\section{REACTION DATA SET ID'S}

Target(Reaction), (Reaction), Target(Reaction) E=Energy Qualifier COULOMB EXCITATION (Reaction) INELASTIC SCATTERING (HI,XNG)

Target should be the target (isotope or element) symbol Reaction should be a reaction symbol (e.g.) N. P. 


\section{Detailed Field Descriptions}

REACTION DATA SET ID'S (CONT.)

Energy may be one of the following

NUM, NUM Units (for definition of NUM see V.I.)

NUM-NUM Units

THERMAL or TH

RESONANCE or RES

Qualifier may be one of the following

RES

IAR

IAS

\section{EXAMPLES:}

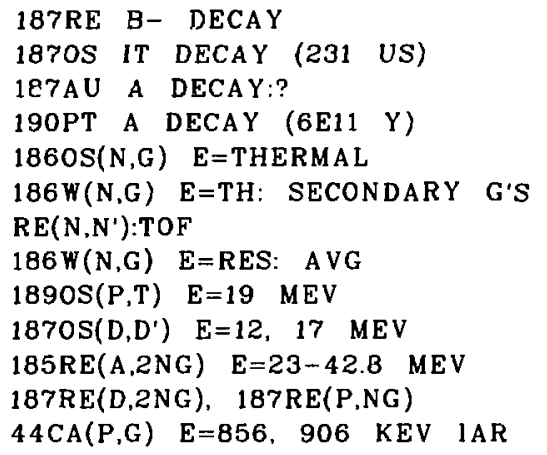

\section{DSREF, KEYNUM, QREF}

The DSREF and QREF fields may include up to three key numbers (KEYNUM) each of which refers to a particular publication. Additional key numbers may be placed in COMMENT records. Key numbers must be left-justified and separated by commas with no blanks between the comma and the reference. A reference key number must be of the form YYAABB where YY is a two digit integer, $A A$ are two alphabetic characters and $B B$ is either a two digit integer or consists of two alphabetic characters. Examples: 81TU01, B1TUXY, etc.

\section{PUB}

Publication information consists of the year of the A-chain publication in Nuclear Data Sheets denoted by two digit year indicator followed by three-character code NDS. This may optionally be followed by a comma and the initials of the persons modifying the data set after its publication. Example 78NDS, WBE or B1NDS.

\section{E. DATE}

This field is of the form YYMMDD where YY, MM and DD are two digit integers within the following ranges $00 \leq Y Y \leq 99,01 \leq M M \leq 12$ and $01 \leq \mathrm{DD} \leq 31$. 


\section{F. RT'YPE}

RTYPE is a single-letter code in col. 8 that gives a name to the RECORD type.

\begin{tabular}{ll} 
RTYPE & \multicolumn{1}{c}{ Description } \\
Blank & $\begin{array}{c}\text { May be IDENTIFICATION record, general } \\
\text { COMMENT record, or END record }\end{array}$ \\
N & NORMALIZATION record \\
P & PARENT record \\
Q & Q-VALUE record \\
L & LEVEL record \\
G & GAMMA record \\
B & BETA (B-) record \\
E & EC (or EC + B B $^{+}$record \\
A & ALPHA record \\
R & REFERENCE
\end{tabular}

\section{G. CI'EXT}

This field consists of free text. The various expressions used in CTEXT can be translated via dictionary lookup. The translation dictionary is given in Appendix $B$. The unit expression used in translation is the string of characters between adjacent "delimiters". Tho characters presently used as "delimiters: are:

$b($ blank),(comma) b(period followed by a blank): ()$-=+\langle>/$ and $\$$

In some cases the dictionary lookup programs look beyond the next delimiter for proper translation.

\section{H. SYM(FLAG)}

The SYM(FLAG) field (with FLAG given) is valid only for secords with RTYPE: L, G, B, E, A.

However, SYM (without FLAG) may be used for records with RTYPE: L, G, B, E, A, N, P, Q.

FLAG can be a string of characters optionally separated by commas. Any character other than a comma and parentheses can be used as a FLAG symbol. For B and E records " $C$ " can not be used for a FLAG as " $C$ " in column 77 of B, E AND A records denotes coincidence. Similarly "*" for $G$ records is reserved to denote multiple placement in the level/decay scheme. 
V. Detalled Field Descriptions

H. SYM(FLAG) (CONT.)

Allowed symbols to be used as SYM for various RTYPE are given below:

RTYPE Allowed SYM

L E, DE, J, T, DT, L, S, DS, BAND, CONF, BE1, BE2, ., G, ISPIN, MOME1, MOME2, ... MOMM1, MOMM2, ... \%EC+\%B+, \%X (X=B-. B+, EC, IT, SF, A, P, or N)

G $\quad E, D E, R I, D R I, M, M R, D M R, C C, D C C, T J, D T I, B E 1, B E 2, \ldots$, BE1W, BE2W, ... BM1, BM2, .., BM1W, BM2W, .., CEK, CEL, CEL1, ... KC, LC, L1C, ... EKC, ELC, EL1C, ... K/L, M/L. $\mathrm{L} 1 / \mathrm{L} 2, \ldots, \mathrm{K} / \mathrm{T}, \mathrm{L} / \mathrm{T}, \ldots$

B E, DE, IB, DIB, LOGFT, DFT, EAV

E E, DE, IB, DIB, IE, DIE, LOGFT, DFT, TI, DTI, EAV, CK, CL, CM, CN+

A E, DE, IA, DlA, HF, DHF

N NR, DNR, NT, DNT, BR, DBR, NB, DNB

P E, DE, J, T, DT, QP, DQP

Q Q-, DQ-, SN, DSN, SP, DSP, QA, DQA

1. CC, NR, NT, BR, NB, QP, LOGFT, HF

These fields consist of either a blank or a single unsigned number (NUM) in one of the following forms:

1. An integer (e.g., 345)

2. A real number (e.g., 345.23)

3. An integer followed by an integer exponent (e.g.. 345E-4, 4E5)

4. A real number followed by an integer exponent (e.g., 345.E-4)

Note: It is desirable to write a number as ' $0.345^{\prime}$ rather than '.345'. However, even if the leading ' $O$ ' were omitted, presumably to save space, it will appear with a leading ' $O$ ' in the NDS output. 


\section{v. Detailed Field Descriptions}

\section{J. Q-, SN, SP, QA, MR}

These fields have the same form as the quantities in V.I. above with the difference that they are allowed to be negative as well.

K. DNR, DNT, DBR, DNB, DQP, DQ-, DSN, DSP, DQA, DE, DRI, DTI, DIB, DIE, DCC, DIA, DS

These one or two characte. fields, represent uncertainty in the "standard" form in the given quantity. The "standard" numeric uncertainty denotes an uncertainty in the last significant figure(s), for example, $N R=0.873$, INR=11 represent a normalization factor of $0.873 \pm 0.011$, similarly $Q P=2.3 E 6$. $D Q P=10$ stand for a $Q-v a l u e$ of $(2.3 \pm 1.0)=10^{6}$ (see also Appendix D-1). The non-numeric uncertainty, e.g, $<,>$, or $\geq$, etc. is denoted by expressions LT, GT, and GE, etc.

The allowed forms for these fields are summarized below:

1. Blank

2. An integer $\leq 99$, preferably $\leq 25$, (left or right justified)

3. One of the following expressions:

LT, GT, LE, GE, AP, CA, SY

for less than, greater than. less than or equal to greater than or equal to, approximately equal to, calculated, and from systematics, respectively.

\section{DFT. IHF, DMR, DT}

These fields allow for the specification of "standard" asymmetric uncertainty. For example, $T=4.2 \mathrm{~S} D T=+8-10$. represent a half-life =4.2+0.8 $\mathrm{s}$. similarly $M R=-3 \quad D M R=+1-4$ represent mixing ratio=-3+1 meaning a range from -7 to -2 . (Note: asymmetric uncertainties add algebraically.) When the +'- construction is missing from this field, the digits or the expressions given in this field represent either the numeric "standard" symmetric or the non-numeric uncertainty as described in V.K. above.

To summarize this field, there are two cases:

1. Symmetric uncertainty - the field consists of an integer number or an expression of the type described in $K$. above.

2. Asymmetric uncertainty - the field is of the form $+x-y$, where $x$ and $y$ are integers. 


\section{Detailed Field Descriptions}

M. RI, TI, IB, IE, IA

The following numbers/expressions are valid for these fields:

1. NUM (number as defined in I. above)

2. (NUM)

Note: Parentheses denote that the number given has been deduced (not directly measured) or taken from other experiment(s).

N. $\mathbf{I}$

The field for half-life $T$ must have one of the following forms:

1. NUM-Blank-Units (i.e. number as defined in V.l. above followed by a blank and its units)

Valid symbols for units are:

Y, D, M, S, MS, US, NS, PS, FS, AS, EV, KEV, and MEV

for year, day, minute, second $(\mathrm{s}), 10^{-3} \mathrm{~s}, 10^{-6} \mathrm{~s}, 10^{-8} \mathrm{~s}, 10^{-12} \mathrm{~s}$. $10^{-15} \mathrm{~s}, 10^{-18} \mathrm{~s}, \mathrm{eV}, 10^{3} \mathrm{eV}$, and $10^{6} \mathrm{eV}$, respectively.

2. Word "STABLE"

Note:A question mark following half-life denotes that the assignment to that level is not certain. A comment should be given to explain the exact meaning intended.

\section{O. ORG, END}

These one character fields can either be blank or have character " $C$ " to denote coincidence.

\section{P. UN}

This two character field can either be blank or have an integer between 1 and 9 followed by character " $U$ ".

\section{Q. MS}

This two character field can either be blank or have character "M" followed by a blank or a digit between 1 and 9 . 


\section{Detailed Field Descriptions}

R. E

An energy field, $E$, can have only one of the following forms:

1. NUM (as defined in V.I. above)

2. $N U M+A$ or $A+N U M$, where $A=X, Y, Z, U, V$, or $W$ used in this order, i.e., for the first occurrence an ' $\mathrm{X}$ ' is used, for its second ocrurrence a ' $\mathrm{Y}$ ' is used, and so on.

3. $N U M+N U M$

4. A (as defined in 2.)

Note: Parentheses are allowed for this field. They denote that the number given has been deduced (not direclly measured) or taken from other experiment(s). Any other interpretation should be explained.

S. $\mathbf{M}$

The multipolarity field can be one of the following:

1. Mult

2. Mult + Mult

3. Mult,Mult

4. NOT Mult

5. IF Mult

Where Mult $=E_{L}$ or $M_{L^{\prime}}$ (where $L$. $L^{\prime}$ are single digits $-L \geq 0, L^{\prime} \geq 1$ ) or $M_{L}+E_{L}$ or $E_{L}+M_{L}$ or $D$ or $Q$

Note: Parentheses in the multipolarity field denote that the assignment is probable and not definite. 


\section{Detailed Field Descriptions}

T. J

The spin-parity field can have only one of the following forms:

1. JPl

2. JPI OR JPI ( $\because$ (comma) can be used in place of 'OR')

3. JPI AND JPI ('\&' (ampersand) can be used in place of 'AND')

4. JPI TO JPI (' $:$ ' colon) can be used in place of 'TO')

Note: If parity is given in the range it will be interpreted as follows:
a. J to J'PJ
means $\mathrm{J} \leq \mathrm{J} \leq \mathrm{J}^{\prime}$ and $\pi=\mathrm{PI}$
b. JPI to J'Pl'
means $\mathrm{JPI}, \mathrm{J}=\mathrm{J}+1 \quad \mathrm{PI}= \pm \ldots, \mathrm{J}=\mathrm{J}^{\prime}-1 \quad \mathrm{PI}= \pm . \mathrm{J}^{\prime} \mathrm{PI}$
c. JPI to J'
means $\quad \mathrm{JPI}, \mathrm{J}=\mathrm{J}+1 \quad \mathrm{PI}= \pm \ldots, \mathrm{J}=\mathrm{J}^{\prime}-1 \quad \mathrm{PI}= \pm, \mathrm{J}^{\prime} \quad \mathrm{PI}= \pm$

Examples:
a. 3 to $6-$ means $\mathrm{J} \pi=3-, 4-, 5-, 6-$
b. $3+$ to $6-$ means $\mathrm{J} \pi=3+, 4 \pm, 5 \pm, 6-$
c. $3+$ to 6 means $\mathrm{J} \pi=3+, 4 \pm, 5 \pm, 6 \pm$

5. OP JPI where OP $\equiv<$, LT, LE, >, GT, GE

Note: This will be interpreted as $\pi=P I$ and $J$ is OP $J$

Example: $<5+$ means $\pi=+$ and $\mathrm{J}<5$

6. NOT JPI

7. NATURAL/UNNATURAL

$$
\begin{aligned}
& \text { In the above } J=N \text { or } N / 2(N \text { is a positive integer }) \\
& \mathrm{PI}=+ \text { or } \\
& \mathrm{JPI}=\mathrm{J} \text { or } \mathrm{PI} \text { or } \mathrm{J} \text { followed by } \mathrm{PI}
\end{aligned}
$$

Note: 1. Parentheses in the $J^{\pi}$ field indicate that the parenthesised value(s) is (are) based upon weak arguments. See "Bases for Spin and Parity Assignments" - Appendix D-4.

Note that $\mathrm{JPl}=(3,4)-$ is interpreted as $\mathrm{J}=(3)$ or $(4)$ and $\pi=-$.

2. As far as possible do not give more than three JPI values.

3. The ranges such as $3-$ to $5+$ are better written as $3-, 4,5+$.

\section{U. $\mathbf{S}$}

This field may contain no more than three S-values, in the form of NUM defined in V.I. separated by commas for corresponding L-values given in the L-field (col. 65-74).

\section{L}

This field may contain no more than three integer numbers (with or without parentheses) separated by commas. Parentheses will be interpreted to mean probable but not definite values. 


\title{
APPENDIX A
}

EXAMPLES OF INPUT/OUTPUT IN ENSDF/Nuclear Data Sheols

\author{
Appendix A-1 \\ ENSDF INPUT \\ Appendix $A-2$ \\ OUTPUT - TABLES \\ Appendix A-3 \\ OUTPUT - PLOT
}

$A P P-A-i$ 


\section{APPENDIX A-1}

\section{ENSDF INPUT}

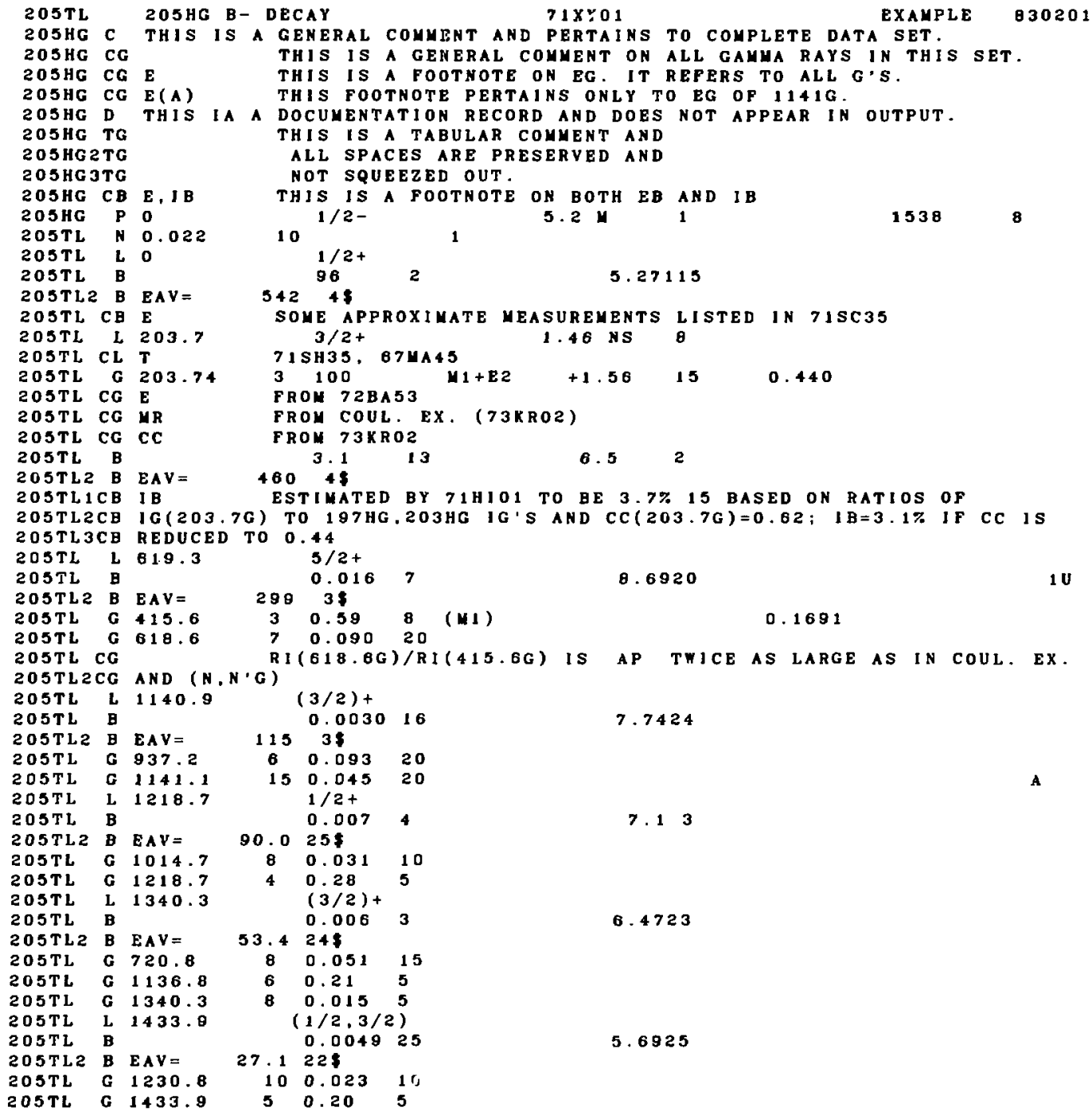




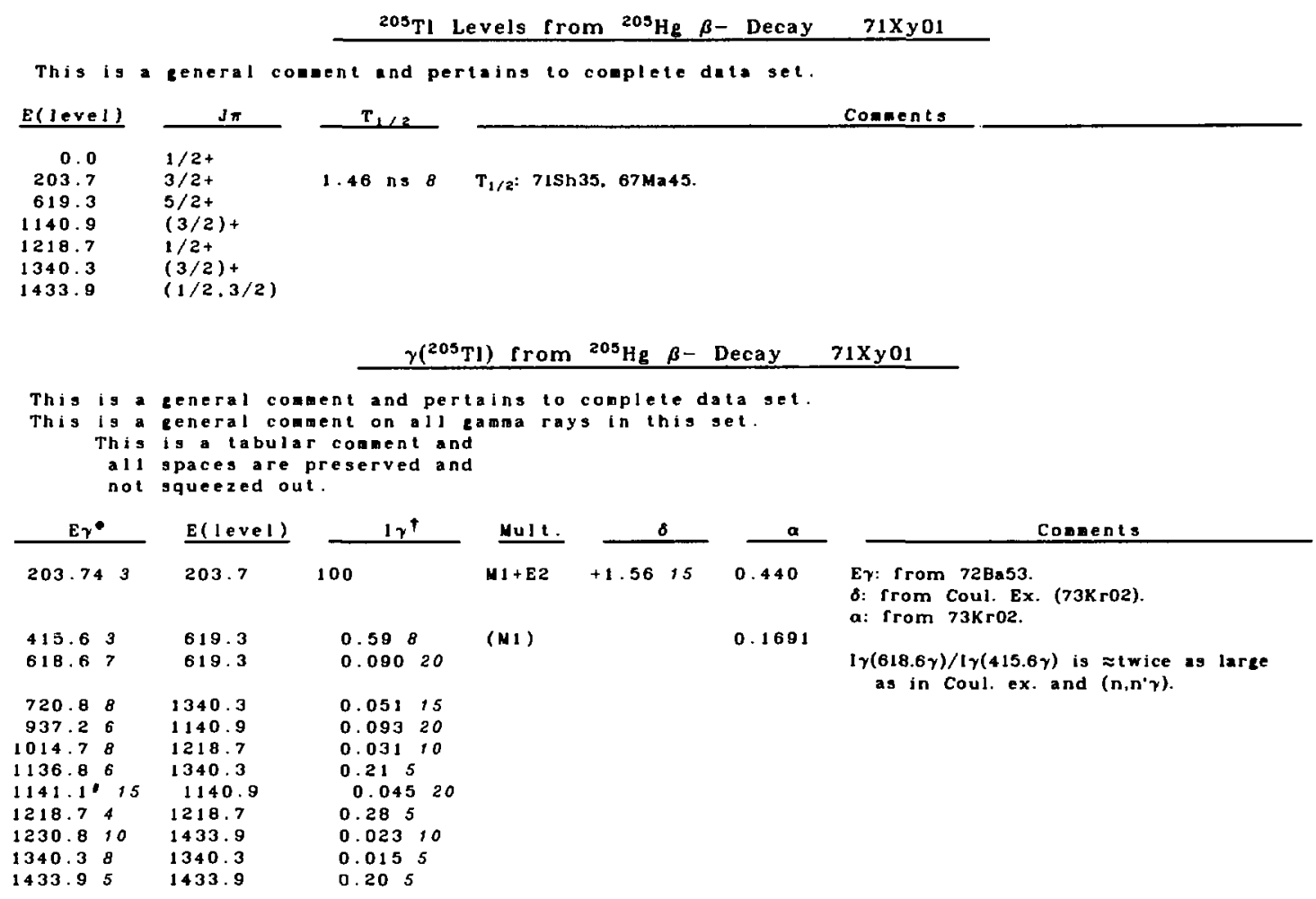

$\uparrow$ For absolute intensity per 100 decays, multiply by 0.02210 .

(a) This is a rootnote on Ey. It refers to all $\gamma^{\prime} s$.

\#This footnote pertains only to Er of $1141 \gamma$.

- $\beta$-radiations from ${ }^{205} \mathrm{Hg} \beta-$ Decay ${ }^{2} \mathrm{Xy}_{01}$

This is a general coment and pertaing to completedita set.

\begin{tabular}{|c|c|c|c|c|}
\hline \multicolumn{2}{|c|}{$\mathrm{E} \beta-\bullet$} & E( level) & $1 \beta-10$ & $\log _{f t}$ \\
\hline$(104$ & 8) & 1433.9 & 0.004925 & 5.69 \\
\hline$(198$ & 8) & 1340.3 & 0.0063 & 6.4723 \\
\hline$(319)$ & 8) & $121 \% 7$ & 0.0074 & 7.13 \\
\hline$(397)$ & 8) & 1140.9 & $0.0030 \quad 16$ & $7.74 \quad 24$ \\
\hline$(919$ & 8) & 619.3 & 0.0167 & 6. 691420 \\
\hline (1334 & 8) & 203.7 & 3.113 & 6.52 \\
\hline
\end{tabular}

$(15388)$

962

5.27115

$\uparrow$ For $\beta$ - intensity per 100 decays. multiply by 1.00 .

* This is a rootnote on both $E \beta$ and $1 \beta$. 
APPENDIX $K-3$

PLOT OUTPUT

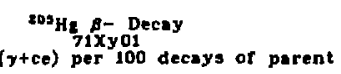

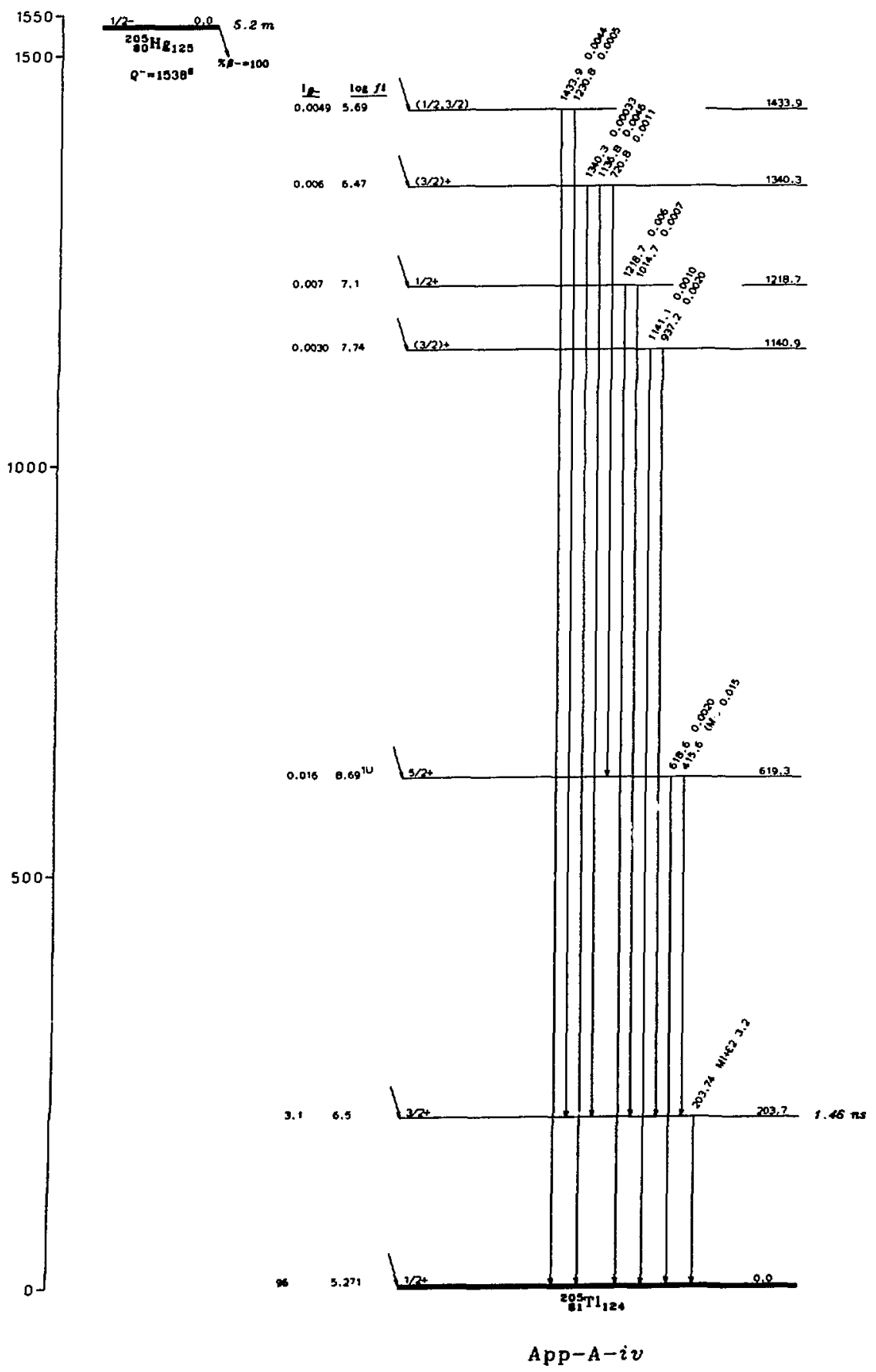




\title{
APPENDIX B
}

\section{ENSDF TRANSLATION DICTIONARY}

\author{
The publication programs translate the text of comments (CTEXT in \\ Section IIl.B) from the computer-readable ENSDF input into printed \\ output for Nuclear Data Sheets. \\ The translation dictionary, as of February 1983, is given below. The \\ dictionary is constantly enlarged and improved as new needs are encountered.
}


APPENDIX B (cont.)

\section{ENSDF}

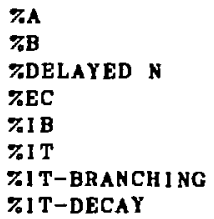

\%IT-DECAY

$\% 1 \mathrm{~T}=$

\%MI

\%SF

$(1+\mathrm{CC})$

$(160,5 \mathrm{~N})$

(A)

(B)

(B+)

$(\mathrm{B}++\mathrm{EC})$

(B-)

(BB)

$(D, Q)$

(DOWN)

$(\mathrm{EC}+\mathrm{B}+$ )

(G)

(GO)

(H,T)

(IT)

(K)

(L)

(N)

$(M, N, O+)$

(ML)

(NE)

(023)

(Q)

(T)

(THETA, H)

(THETA, H, TEMP)

(UP)

$\because 2$

$A=(1 / 3)$

G2

- $R$

- sigma

- T1/2

- W I DTH

1.33LC

$2 \mathrm{~J}$

2MC2

$4 \mathrm{PI}$

$4 P I B$

4P I BG

A DECAY

A SYST

A'

A)

A.

$A-N$

A-SYST

A)

AO

A1

$\mathbf{A}$

A3

A4
ENSDF D I CT I ONARY

TRANSLATION

$7 \alpha$

$7 \beta$

Fde I ayed n

$7 \varepsilon$

$\% 1 \beta$

\%1T

TIT-branching

FIT-decay

\%I $\mathrm{T}=$

\%N1

7SF

$(1+a)$

(100,5n)

(a)

(B)

$\left(\beta^{+}\right)$

$(c+\beta+)$

$\left(\beta^{-}\right)$

$(\beta \beta)$

$(D, Q)$

(d)

$(\varepsilon+\beta+)$

$(\gamma)$

$\left(\gamma_{0}\right)$

$(H, t)$

(IT)

(K)

(L)

(M)

$(M, N, O+)$

(ML)

$(\neq)$

(023)

(Q)

(t)

$(\theta, H)$

$(\theta, H, T)$

(t)

2

$\times A^{1 / 3}$

$\mathrm{B}_{2}$

R

$\rightarrow \sigma$

$* T_{1 / 2}$

$\Gamma$

I. 33a (i)

2.

$2 m c^{2}$

$4 \pi$

$4 \pi \beta$

$4 \pi \beta \gamma$

$\alpha$ decay

a syst

$a^{\prime}$

a)

$a$,

$A-\mathrm{N}$

a-syst

$\alpha /$

$A_{0}$

$A_{1}$

$A_{2}$

$A_{3}$
ENSDF

$\mathbf{A}=$

AAS

$A C E$

AG

AJ

AlAGA

ALPHA

ALPHAS

ANT I-COMPTON

AP

APR I L

AUGER

AUGUST

AUSTERN

AXK

AY

B

B (E1

B(E1)

$B$ (E2

$B$ (E2)

$B$ (E3

$B$ (E3)

B* $R$

$\mathrm{B}+$

Bo

B2

$B 2 * \mathrm{R}$

$\mathrm{B} 20$

B22

B3

B3. $\mathrm{A}$

B30

B4

B4* $\mathrm{A}$

B5

B6

B7

$\mathrm{B}=$

BCE

$\operatorname{BCE}(T)$

BEO

BE 1

BE 1 W

BE2

BE2UP

BE2W

BE3

BE3W

BE4

BE4W

BE5

BEL

BELW

BERKELEY

BESSEL

BETA

BETA (T)

BETA * $R$

BETAS

BF3

BG

BIEDENHARN

BJ $\cdots 2$

BI
TRANSLATION

$A=$

AAS

(a) (ce)

$\alpha \gamma$

AJ

Alaga

$a$

$\alpha$ 's

ant $\mathbf{i}$-Compton

$\approx$

Apri I

Auger

August

Austern

(a) (k X-ray)

Ay

$\boldsymbol{B}$

B( E)

$B(E 1)$

$B$ (E2)

B ( E2)

B ( E3

B (E3)

$\beta \mathbf{R}$

$\beta^{+}$

$\beta_{0}$

$\beta_{2}$ R

$\beta_{20}$

$\beta_{22}$

$\beta_{3} R$

$\beta_{30}$

$\beta_{4}$

$\beta_{4} R$

$\beta_{5}$

$\beta_{8}$

$\beta_{7}$

$B=$

Bce

Bce (t)

$B(E O)$

B(E1)

$B(E l)(W . u$.

$B(E 2)$

$B(E 2)$ ?

$B(E 2)(W . u$. )

$B(E 3)$

$\mathrm{B}(\mathrm{E3})(\mathrm{F} . \mathrm{u}$. )

$\mathrm{B}(\mathrm{E} 4)$

$\mathrm{B}(\mathrm{E} 4)(\mathrm{W} . \mathrm{u}$.

$B(E 5)$

$B(E L)$

$B(E L)(w . u$.

Berkeley

Bessel

$\beta$

$\beta(\mathrm{t})$

$\beta \mathbf{R}$

$\beta$ 's

$\mathrm{BF}_{\mathbf{3}}$

By

Biedenharn

$\mathrm{BJ}^{2}$

$\beta_{1}$ 
APPENDIX B (cont.)

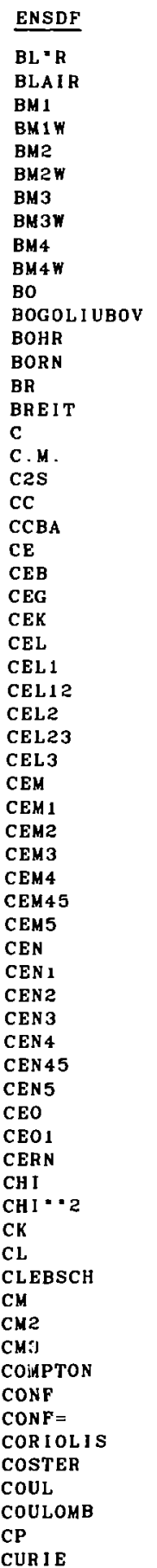

TRANSLAT ION

$\beta_{L} \mathrm{R}$

Blair

B(MI)

$B(M I)(W . U$.

$B$ (M2)

$B($ M2) (W.u.)

$\mathrm{B}$ (M3)

$B(M 3)$ (H. u.)

$B(\mathrm{M} 4)$

$B\left(M_{4}\right)\left(W . U_{.}\right)$

Bo

Bogoliubov

Bohr

Born

Branching

Breit

C

c.m.

$c^{2} \mathrm{~S}$

$\alpha$

CCBA

ce

ce $\beta$

cer

ce (K)

ce (L)

ce (L1)

ce (L12)

ce(L2)

ce(L23)

ce (L3)

$\operatorname{ce}(\mathrm{M})$

ce (M1)

ce (M2)

$\mathrm{ce}$ (M3)

ce (M4)

ce (H45)

ce (M5)

$c e(N)$

ce (N1)

ce (N2)

ce (N3)

ce (N4)

ce (N45)

ce (N5)

ce (0)

ce (01)

CERN

$x^{2}$

$x^{2}$

$\varepsilon$ L

Clebsch

$\Sigma M$

$\mathrm{cm}^{3}$

Compton

configuration

configuration=

Coriolis

Coster

Coul

Coul omb

CP

Curie
ENSDF DICTIONARY

2-Feb-83

ENSDF

D)

$D+Q$

DBR

DCC

DE

DECEMBER

DEG

DELTA

DFT

DHF

DIA

DIB

DIE

DJ

DK

DL

DMR

DNR

DOMEGA

DOPPLER

DPAD

DQ+

DQA

DR I

DS

DS/ DW

DSA

DSAM

DSIGMA

DT

DT $1 / 2$

DT I

DWBA

DW 1 A

DWUCK

E

$E(A)$

$E(D)$

E (E)

$E(N)$

E (P)

$E(T)$

$E=1 / 2$

E+

E-

E. G .

$\mathrm{E} / \mathrm{DE}$

EO

E 1

E1 *

E2

E2 $•$

E3

E3*

E4

E4 *

EA

EAV

EB

EB (

EC

ECC

ECE

ECK

ECL

\section{TRANSLATION}

D)

$D+Q$

branching uncertainty

$\Delta \alpha$

$\Delta E$

December

$\Delta(\log f t)$

$\Delta(\mathrm{HF})$

$\Delta \mathrm{I} \alpha$

$\Delta \mathrm{I} \beta$

$\Delta 1 \varepsilon$

$\Delta \mathbf{J}$

$\Delta K$

$\Delta \mathbf{L}$

$\Delta \delta$

$\Delta(\gamma-$ normalization $)$

d $\Omega$

Doppler

DPAD

$\triangle Q+$

$\Delta Q \alpha$

$\Delta \mathbf{l} \gamma$

$\Delta S$

$\mathrm{d} \sigma / \mathrm{d} \Omega$

DSA

DSA

d $\sigma$

$\Delta T_{1 / 2}$

$\Delta \mathrm{T}_{1 / 2}$

$\Delta I(\gamma+c e)$

DWBA

DWIA

DWUCK

E

$E(\alpha)$

$E(d)$

$E(e)$

$E(n)$

$E(p)$

$E(t)$

E $1 / 2$

e+

e-

e. $g$

$\mathrm{E} / \Delta \mathrm{E}$

EO

E 1

E1*

E2

$\mathrm{E2}$ *

E3

E3.

E4

E4.

Ea

$\operatorname{avg} E \beta$

$E \beta$

$\varepsilon \mathrm{B}$ (

$\alpha(\exp )$

E(ce)

$\varepsilon \mathrm{K}(\exp )$

cL (exp) 
APPENDIX B (cont.)

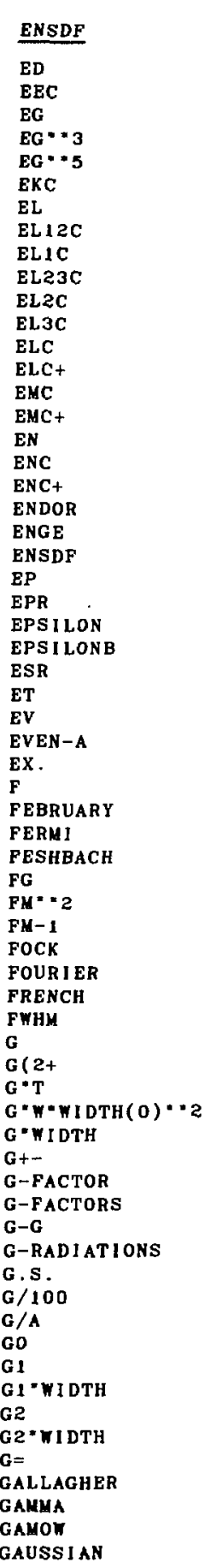

TRANSLATION

E(d)

Ec

Ey

$\mathrm{E} \gamma^{3}$

E $\gamma^{5}$

$\alpha(K) \exp$

EL

$\alpha(L 12) \exp$

$\alpha(L 1) \exp$

a(L23) exp

$a(L 2) \exp$

$a(L 3) \exp$

a (L) exp

$a(L+\ldots) \exp$

$\alpha(M)$ exp

$\alpha(M+\ldots) \exp$

$E(n)$

$\alpha(N) \exp$

$a(N+\ldots)$ exp

ENDOR

Enge

ENSDF

$E(p)$

EPR

$\varepsilon$ B

ESR

$E(t)$

eV

even-A

Ex.

$F$

February

Fermi

Feshbach

(fragment) $\gamma$

$f \mathrm{~m}^{2}$

$\mathrm{fm}^{-1}$

Fock

Fourier

French

FWHM

$\gamma$

g( $2+$

$\mathrm{gT}$

$g \sim \Gamma^{2}(0)$

g $\Gamma$

$\gamma^{*}$

g-ractor

g-factors

$\boldsymbol{\gamma}-\boldsymbol{\gamma}$

$\gamma-r a d i a t i o n s$

g.s.

$\gamma / 100$

$\gamma / \alpha$

$\gamma_{0}$

$e_{1}$

$\mathbb{R}_{1} \Gamma$

$\mathbb{R}_{2} \Gamma$

Gallagher

$\gamma$

Gamow

Gausis an

\section{ENSDF DICTIONARY}

2-Feb-83

ENSDF

GB-

$\mathrm{GCE}$

GDR

$G E$

GE (LI)

GEL I

GEV

GG

GGG

GLENDENN I NG

GORDAN

GQR

GS

GT

H)

H.

$\mathrm{H}=$

HAGER

HARTREE

HAUSER

HF

HI

1

I . E .

IA

I A R

IAS

I B

IB+

IB-

I BA

I BS

ICC

ICE

ICE (N)

IE

$1 \mathrm{EC}$

IG

I MPAC

IN (

IPAC

ISOLDE

ISPIN

ISPINZ

IT DECAY

IT DECAYS

$1 \mathrm{~T}-$

$I T=$

$\mathrm{J}$

$\mathrm{J}=\mathbf{2}$

Jo

$\mathrm{J} 2$

JANUARY

JF

J I

JMAX

JMIN

JOSEF

JPI

JULY

JUNE

$\mathrm{K}$

$\mathrm{K} / \mathrm{l}+\mathbf{H}$

$\mathrm{K} / \mathrm{T}$

KAPPA
TRANSLATION

$\gamma \beta-$

$\gamma$ ce

GDR

$\geq$

Ge (Li)

Ge(Li)

GeV

$\gamma \gamma$

$\boldsymbol{\gamma \gamma \gamma}$

Glendenning

Gordan

GQR

s. 3 .

$>$

H(

H,

Hager

Hartree

Hauser

HF

H 1

1

i.e

la

I AR

IAS

I $\beta$

$\boldsymbol{I} \beta+$

I $\beta-$

IBA

IBS

$\alpha$

Ice

Ice(N)

I $\boldsymbol{c}$

I $\boldsymbol{c}$

Ir

IMPAC

In (

I PAC

ISOLDE

$T$

$T_{z}$

IT decay

IT decays

$1 \mathrm{~T}-$

$\mathrm{IT}=$

J

$\mathrm{J}^{2}$

$J_{0}$

$J_{2}$

January

$\mathbf{J} \mathbf{f}$

$\mathrm{Ji}$

$\mathrm{J} \max$

J m i n

JOSEF

$J \pi$

JuJy

June

K

$\mathrm{K} / \mathrm{L}+\mathrm{H}$

$\operatorname{ce}(K) /(\gamma+c e)$

$\boldsymbol{\kappa}$ 
APPENDIX B (cont.)

\section{ENSDF DICTIONARY \\ 2-Feb-83}

TRANSLATION

ENSDF

$\mathrm{KC}$

KEV

KEVIN

KG

KLL

KN IGHT

KPI

KRANE

KRONIG

KUR I E

KUWA IT

KXY

L

L ( $2 \mathrm{~N})$

$\mathrm{L} / \mathrm{T}$

L 1

L 12

L1C

L2

L2C

L3

L3C

LAMBDA

LASER

LC

LE

LEGENDRE

LM

LMN

LN

LOG F1T

LOG FIUT

LOG FT

LOGF $1 T$

LOGF 1 UT

LOGFT

LOHENGR I N

LORENTZ I AN

$\alpha(K)$

keV

Kelvin

KG

KLL

Knight

$\mathrm{K} \pi$

Krane

Kronig

Kurie

Kumait

KXY

$\mathrm{L}$

$L(2 n)$

$c e(L) /(\gamma+c e)$

L1

L12

$a(L 1)$

L2

$\alpha(L 2)$

L3

a (L3)

LASER

$a(L)$

$s$

Legendre

LM

LMN

L ( n )

$\log f^{\prime} t$

$\log f^{\prime} t$

$\log f t$

$\log f^{\prime} t$

$\log f^{\prime 2} t$

$\log f t$

LOHENGR I N

Lorentzian

L (p)

LT

H

M

$M+=$

$M$,

M-SHELL

M-SUBSHELL

$M / \mathrm{T}$

M 1

M1 *

M1C

$\mathrm{N} 2$

M2*

M2C

M3

M4

$M=$

MAG

MARCH

MB

MB/SR

MC

$\mathrm{MC}+$

MEDLIST

MEV

$<$

m

$M$

$M+=$

$M$,

$M-s h e l 1$

M-subshell

$c e(M) /(\gamma+c e)$

$M 1$

M1 *

$\alpha$ (M1)

M2

M2*

a (M2)

M3

M4

$\mathrm{mult}=$

magnetic

March

$\mathrm{mb}$

$\mathrm{mb} / \mathrm{sr}$

$a(M)$

$\alpha(M+\ldots)$

MEDL IST

$\mathrm{MeV}$

$\mathrm{MeV}^{-4}$

MICROBARN

MICROBARNS/SR

ML

MNO

MOME2

MOMM 1

HOSS

MOSSBAUER

MOSZKOWSK ]

$M R$

$M R=* 2$

MS

MU

N

N)

$\mathrm{N}+/ \mathrm{T}$

$\mathrm{N}$.

$\mathrm{N}$-CAPTURE

N-CAPTURES

N-RESONANCE

$N$-RESONANCES

N-SHELL

N-SUBSHELL

$\mathrm{N}-\mathrm{Z}$

N /

$\mathrm{N} 1 / \mathrm{N}_{2} / \mathrm{N}_{3}$

$\mathrm{N} 1 \mathrm{C}$

$\mathrm{N} 2 \mathrm{C}$

N $3 C$

$\mathrm{N}<$

$\mathrm{N}=$

NA2WO4

NAI

NB

NB/SR

NBS

NC

$\mathrm{NC}+$

NDS

NE

NG

NGG

NILSSON

NMR

NORDHE IM

NOTE :

NOVEMBER

NQR

NR

NT

$\mathrm{NU}$

0

OCTOBER

ODD-A

OMEGA

ORN L

USIRIS

$P$

$P($

P)

P.

$\mathrm{P}-\mathrm{N}$

P-WIDTH

PO

P2NG
TRANSLATION

$\boldsymbol{\mu b}$

$\mu b / s r$

$M+\mathbf{L}$

$\mathrm{M}+\mathrm{N}+\mathrm{O}$

$Q$

M

Moss

Mossbauer

Moszkonski

$\delta$

$\delta^{2}$

$\mu$

N

n)

$\operatorname{ce}(\mathrm{N}+) /(\gamma+\mathrm{ce})$

n.

n-capture

n-captures

n-resonance

$n$-resonances

$\mathrm{N}$-shell

$\mathrm{N}$-subshe 11

$\mathbf{N}-\mathbf{Z}$

N /

N $1 /$ N2 $/$ N3

$\alpha(N 1)$

$\alpha(N 2)$

$\alpha(\mathrm{N3})$

$\mathrm{N}<$

$\mathrm{N}=$

$\mathrm{Na}_{2} \mathrm{WO}_{4}$

$\mathrm{NaI}$

$\beta, \varepsilon$-normalization

$\mathrm{nb} / \mathrm{s} \mathbf{r}$

N BS

$\alpha(N)$

$a(N+\ldots)$

Nuclear Data Sheets

$\neq$

ny

n $\gamma \gamma$

liils son

NMR

Nordhe in

Note:

November

NOR

I $\gamma$-normalization

$l(\gamma+c e)$-normalization

$\nu$

October

odd-A

$\omega$

ORNL

OSIRIS

p

p)

p,

p-n

p-width

$P_{0}$

pin $\gamma$ 
APPENDIX B (cont.)

ENSDF

PAC

PAD

PC

PG

PGG

PH 1

PI

PNG

PR I

PS I

PTBA

Q(

Q+

Q-

Q3D

QA

$\mathrm{R}$ ( DCo)

$R *-2$

RO

RAMAN

RASMUSSEN

RHO

R I

ROSE

$S$

s'

$\mathrm{S}(\mathrm{2N})$

S-FACTOR

S-FACTORS

S-VALUES

s/

$S=$

$S A$

SCHMIDT

SEEGER

SELTZER

SEPTEMBER

SF

SI (LI)

S) GMA

SIGNA

SIGNG

SILI

SN

SP

STEFFEN

SUB-COULONB

SUMOF

sy

$T$

T)

$T$,

T/

$T 1 / 2$

$\mathbf{T}=$
TRANSLATION

PAC

PAD

PC

Pr

pr $\gamma$

$\pi$

pn $\gamma$

$\Delta \mathrm{l} \gamma(\pi)$

PTBA

$Q($

$Q(\varepsilon)$

$Q(\beta-)$

Q3D

$Q(\alpha)$

$R$

R (DCO)

$r^{2}$

$r_{0}$

Raman

Rasmussen

$P$

Iy

Rose

s.

$s($

$S(2 n)$

S-factar

S-factars

S-values

s/

$s(a)$

Schuidt

Seeger

Seltzer

September

SF

Si (Li)

a

$\sigma(n a)$

$\sigma(n \gamma)$

Si $(L i)$

$S(n)$

$S(p)$

steffen

sub-Coulomb

$\Sigma$

syst

$T_{1 / 2}$

t)

t.

T/

$T_{1 / 2}$

$T_{1 / 2}=$
ENSDF DICTIONARY

2-Feb-83

ENSDF

TAU

TELLER

TEMP

THETA

TI

TOF

TRISTAN

TRI UMPH

$\mathrm{U}$

UB

UB' MEV

UB/SR

UK

US

USA

USSR

$v$

U.

WEISSKOPF

TI DTH

WIGNER

WINTHER

$X$

$X($

$X-R A Y$

$X$-RAYS

$X=$

$X G$

$\mathrm{XK}$

$X K A$

$X K A 1$

XKA2

XKB

XKB 1

XKB1P

$X K B 2$

$X K B 2 P$

$X K B 3$

$X K B 4$

$X K G$

$\mathrm{XKO2}$

$\mathrm{XKO3}$

$X \mathrm{~L}$

$X L A$

$X \leq A 1$

$X L A 2$

$X$ LB

$X L B 1$

$X$ LB2

$X$ LG

XLG1

XLG2

$x y$

$Y$

z
TRANSLATION

$T$

Teller

$T$

$\theta$

$I(\gamma+c e)$

TOF

TRISTAN

TRI UMPH

U

$\boldsymbol{\mu b}$

$\mu b=M e V$

$\boldsymbol{\mu b} / \mathbf{s}$

UK

$\mu \mathrm{s}$

USSR

$\mathrm{V}$

พ.u.

We isskopr

$\Gamma$

Wigner

winther

$x$

$x($

$x-r a y$

$x$-rays

$x=$

$\mathrm{Xy}$

$K X$-ray

Ka X-ray

$\mathrm{Ka}_{1} \mathrm{X}$-ray

$\mathrm{Ka}_{2} \mathrm{X}-\mathrm{ray}$

$k \beta X-r a y$

$\mathrm{K} \beta, \mathrm{X}$-ray

$K \beta_{1} \cdot X-r a y$

$K \beta_{2} X$-ray

$K \beta_{2} \cdot X-r a y$

$K \beta_{3} X-r a y$

$K \beta, X-r a y$

$(k X-r a y) \gamma$

$x(02) x-r a y$

K(03)X-ray

L $x-r a y$

La x-ray

La, X-ray

$\operatorname{La}_{2} x-r a y$

$L_{f} \mathrm{X}$-ray

$L \beta_{1} X-r a y$

$L \beta_{2} X-r a y$

$L, X-r a y$

Lr, $x-$ ray

L. $\gamma_{2} X-r a y$

M X-ray

y 
APPENDIX B (cont.)

ENSDF

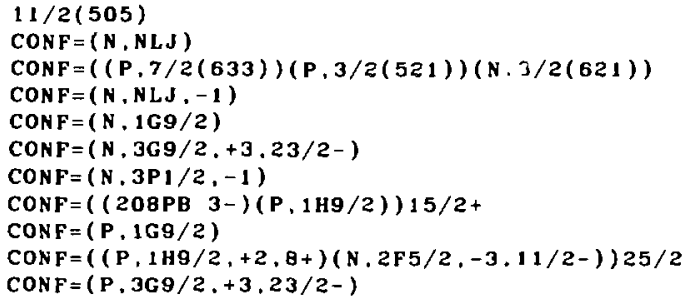

\section{ENSDF DICTIONARY \\ 2-Feb-83 \\ TRANSLATION}

\section{$11 / 2[505]$}

configuration $=(\nu n l j)$

configuration $=((\pi 7 / 2[633])(\pi 3 / 2[521])(\nu 3 / 2[621]))$ configuration $=(u n l j)^{-1}$ configuration $=\left(\begin{array}{ll}\nu & 1 / 8 / 2\end{array}\right)$ configuration $=\left(\nu 3 g_{0 / 2}\right)^{+3} 23 / 2-$ configuration $=\left(\begin{array}{ll}\nu & 3 p_{1 / 2}\end{array}\right)^{-1}$ configuration $=\left((200 \mathrm{~Pb} 3-)\left(\pi 1 \mathrm{~h}_{0 / 2}\right)\right) 15 / 2+$ configuration $=(\pi 18 g / 2)$ configuration $=\left(\left(\pi 1 \mathrm{~h}_{\mathrm{g} / 2}\right)^{2},\left(\nu 2 \mathrm{f}_{3 / 2}\right)^{-3} / 1 / 2-\right) 25 / 2-$ configuration $=\left(\pi 3 g_{9 / 2}\right)+3_{23 / 2-}$ 


\section{APPENDIX C \\ DATA EVALUATION CENTERS}

a. National Nuclear Data Center Brookhaven National Laboratory Upton, NY 11973. U.S.A.

b. Nuclear Data Project Oak Ridge National Laboratory oak Ridge, TN 37830, U.S.A.

c. Isotopes Project Lawrence Berkeley Laboratory Berkeley, CA 94720, U.S.A.

d. Idaho National Engineering Laboratory

E.G. and G. Idaho, Inc.

P.O. Box 1625

Jdaho Falls, ID 83415, U.S.A.

e. Physics Department

University of Pennsylvania Philadelphia, PA 19174, U.S.A.

f. Center for Nuclear Structure and Reaction Dat.a of the U.S.S.R. State Committee on the Utilization of Atomic Energy U.S.S.R.

46 Ulitsa Kurchatova

Moscow, D-182, U.S.S.R.

g. Data Centre

Leningrad Nuclear Physics Inst.

Gatchina, Leningrad Region 188350, U.S.S.R.

h. Fysisch Laboratorium Princetonplein 5. P.P. Box 80000 3508 TA Utrecht. The Netherlands i. Oliver Lodge Laboratory University of Liverpool Liverpool L69 3BX. U.K.

j. Fachinformationszentrum Energie. Mathematik GmbH Kernforschungszentrum D-7514 Eggenstein-Leopoldshafen 2 . F.R.G.

k. Centre d'Etudes Nucleaires DRF-CPN Cedex No. 85 F-38041 Grenoble Cedex, France

1. Division of Physics Japan Atomic Energy Research Institute

Tokai-Mura, Naka-Gun

Ibaraki-Ken 319-11. Japan

m. Institute of Physics

University of Lund

Solvegatan 14

S-223 62 Lund. Sweden

n. Nuclear Data Project Kuwait Institute for Scientific Research P.o. Box 12009

Kuwait, Kuwait

- Laboratorium voor Kernfysica Proeftuinstraat 86 B-9000 Ghent. Belgium

p. Tandem Accelerator Laboratory McMaster University Hamilton, Ontario LBS $4 \mathrm{KI}$ Canada 


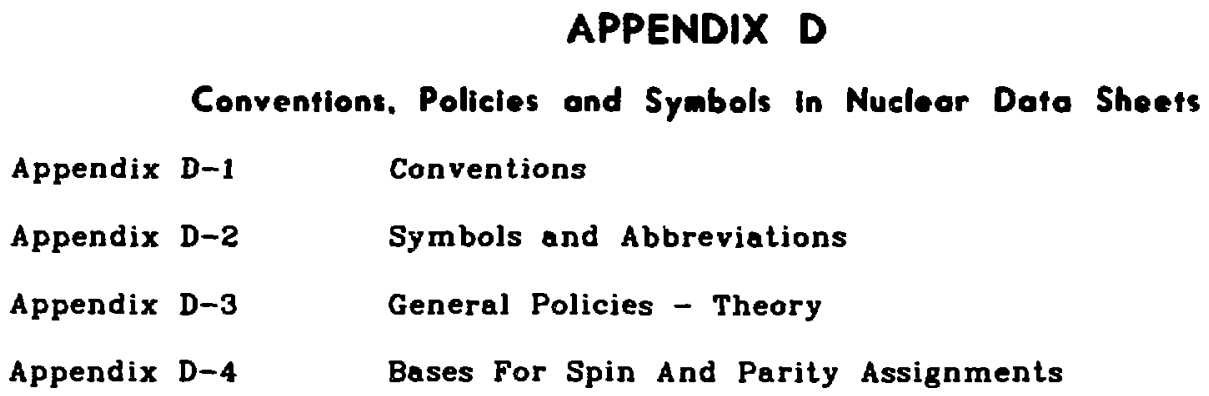


CONYENTIONS USED IN NUCLEAR DATA SHEETS

Unito
Energies.................... kev
Crose sections $\ldots \ldots \ldots \ldots \ldots \ldots \ldots$ barns
Magnetic dipole moments $\ldots \ldots \ldots$ nuclear magnetons
Electric quadrupole moments $\ldots$ barns

Uncortainties ("Brrors") The uncertainty in any number is given one space after the number itself:

$$
\begin{aligned}
& 4.6233 \text { means } 4.623 \pm 0003 \\
& 4.612 \\
& 5.4 \cdot 10^{3} 2 \text { means } 4.6 \pm 1.2 \\
& 4.2+8-10 \text { means } 5400 \pm 200 \\
& -4.2+8-10 \text { means }-(4.2+10.80-8)=-4.2+0.8
\end{aligned}
$$

$?$ Question Marks given arter the energy value or level or adiation represent doubl as to the exiatance of that level or the radiation. A "?" civen after the TI/2 value indicates that the assignment of that half-life to civen level is not certain.

( ) Perentheses have the following interpretation for different quantities in the tabular data:

\section{Quantity}

$J^{*}$

L, Mult.

other

Examples:

$$
J^{\pi}=(1 / 2,3 / 2)^{-}
$$

Weak arzuments limit the spin to $1 / 2$ or $3 / 2$ strong arcuments indicate negative parity.

$$
J^{\pi}=4^{(+)}
$$

Strong arguments show the spin is 4; weak arcuments sugest positive parity.

Mult. $=M I(+E 2)$

Multipolarity is MI with possible admixture of M2.

\section{[ ] Brackets}

$7 / 2^{-[514]}$ Nilsson asymplotic quantum numbers, $K *\left[N n_{x} \Lambda\right]$

Lerel Scheme Symbols

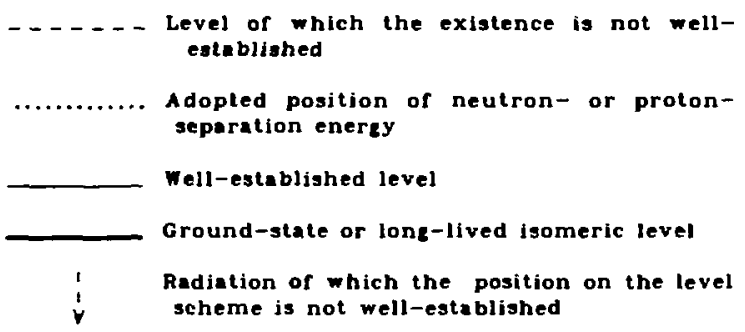

An expected strong transition that has not been $\dot{y}$ observed

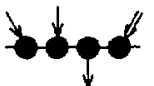

Beta, camma, and alpha ray entering level are coincident with lamma ray leavine level
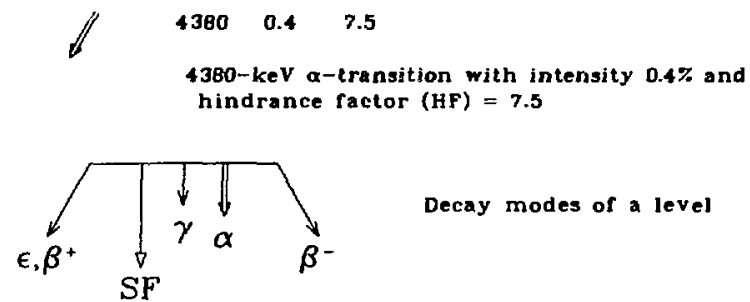

$\ \quad 404 \quad 48.5$ $\beta^{-}-$transition with endpoint energy, 404
keV measured directly; intensity. $4 \%$ of decays, usually round indirectly (from $\gamma$-intensities, a more accurate method ir there are several a-proups); $\log f t=8.5$

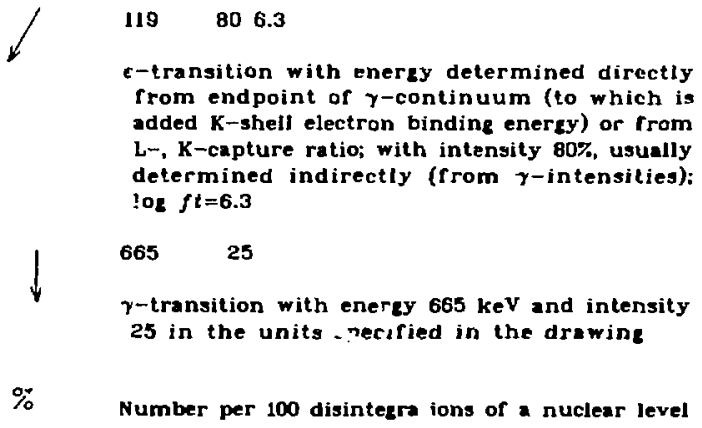




\section{Nuclear Date Sheets Symbola and Abbreviations}

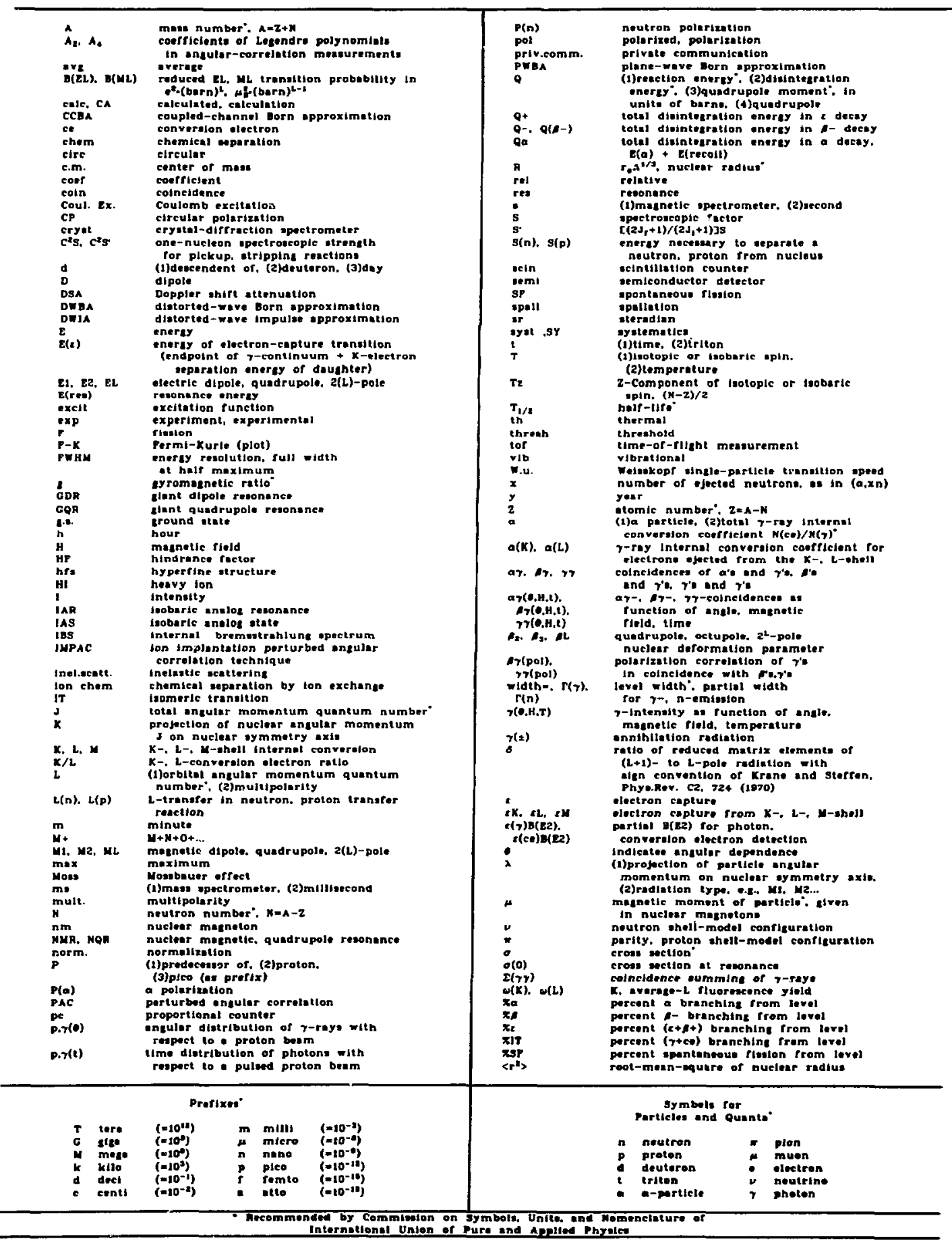




\section{GBNBRAL POLICIBS - "THBORY"}

A reference "Theory $67 \times y 01 "$ indicates theoretlcal predictions computed by the authors of $67 \mathrm{xy01}$. A reference "Theory" alone Indicates a determination by the compiler of theoretlcal predletions described below.

\section{Internal Converaion Coefficiente}

Theoretical conversion coefficients are obtained by spline interpolatlon (68Ha53) from tables of Hager and Seltzer (68Ha63) for the $K-, L_{1 \ldots . .}-, M_{1} \ldots s^{-g h e l l s}$ and of Drogoun, Plajner, and Schmutzler (71Dri1) for the $(\mathrm{N}+\mathrm{O}+\ldots)-$ shells. For the $\mathrm{N}_{1 . . .5}-\mathbf{s u b s h e l l s ,}$ values are obtajned by graphical interpolation from tables of Dragoun, Pauli, and Schmutzler (69Dr09). For $K-, \mathrm{L}_{1 . . .3}$-shells, conversion coefricients for transitions outside the $E_{r}$. $\Lambda-$, or $Z$-ranges of Hacer and Seltzer are obtained as rollows: ror $E, 56000$ keV and for $Z=3,6,10$ and 14sZs30 interpolation from tubles of Band et a!. $(76 \mathrm{Ba} 63)$; for $\mathrm{E}_{\gamma}>2600 \mathrm{keV}$, by craphlcal interpolation from tables of Trusov (72Tr09). For EO-transitions, $K / L_{1}$ and $L_{1} / L_{2}$ ratios are obtained by eraphical Interpolation from tables of Hager and Seltzer (69Ha61).

\section{Anguler Distribution and Correlation Coefricients}

The coefricients $A_{k}(\delta)$ required for analysis of directional correlation, polarization correlation, directional distribution, and polarization distribution data are obtained as described by Steffen (71St47, 71St48). In particular, we adopt the phase convention for the mixine ratio, 6 , defined by the authors (70Kr03). Particle parameters required for the analysis of correlation and distribution data involvix: conversion electrons are oblained by graphical interpolation from tables of Hager and Seltzer (68Ha54). The expression for the deorientation coefficient required to account for intermediate unobserved mixed radiations is piven by Anicin (72An20)."

A tabulation of gamma-camma directional coefficients is given by Taylor, et al. (71Ta32). These authors use the Stefren phase convention.

\section{Penetration Parameters}

Penetration paramelers required for the analysis of internal conversion data and gnzuiar correlation or distribution datu involvine electrons are obtained by eraphical interpolation from tables of Hager and Seltzer (69Ha61).

\section{Internal Pair Conversion Coefficients}

Theoretical internal pair converslon coefficients for $\Lambda=E 1, M 1, E 2$ are obtained by eraphical interpolation in 2, E from tables of Lombard, et al. (6BLo16).

\footnotetext{
- As pointed out by these suthors, most earjier references which
} diecusa this coefriclent define it incorrectly

\section{B-Decay Rate Probabilities}

Los ft values, capture-to-positron ratios, and electron-capture ratios for allowed, first-forbidden unique, and second-forbidden unique transitions are obtained as described by Gove and Martin (71Go40). This reference also contains tabulation of loe $f$ values and total capture-to-positron ratios for allowed and first-forbidden unique transitions.

\section{Atomic Processes}

$x$-ray fluorescence yields are obtained from Bambynek et al. (72Bb16) for $\mathrm{Z} \leq 92$ and from Ahmad (79Ah01) for $\mathrm{Z}>92$.

Electron binding enereies for $\mathrm{Z}<84$ are taken from Bearden and Burr (67Be73) and from Porter and Freedman (78Po08) for $2>84$.

\section{a-Decay HIndrance Factors}

The $a$-hindrance factors (the ratio of the measured partial half-life for a-emission to the theoretical half-life) are obtained from the spin-independent equations of Preston (47Pr17). The nuclear radius for each even-even : ucleus was determined by defining, for the e.s. to g.s. a-transition hindrance factor, HF $\equiv 1$. For odd-A and odd-odd nuclei, the radius was chosen to be the average of the radii for the adjacent even-even nuclei (72E121). In the few cases where only one adjacent eveneven radius was known, that value was corrected for the $A^{1 / 3}$ mass dependence and used in the calculation.

\section{Electromagnetic Transition Rates}

The Weisskopf single-particle estimates for the halflives of electric and magnetic multipole radiation of energy $E_{\gamma}$ are (52B187)

$T_{1 / 2 W}(E L)=0.190\left(\frac{L}{L+1}\right)\left(\frac{3+L}{3}\right)^{2} \frac{[(2 L+1) ! !]^{2}}{A^{2 L / 3}}\left(\frac{164.44}{E_{\gamma}(M e V)}\right)^{2 L+1}=10^{-21} s$

$T_{1 / 2 W}(M L)=3.255 A^{2 / 3} T_{1 / 2 W}(E L)$

for nuclear radius $1.2 \mathrm{~A}^{1 / 3} \cdot 10^{-13} \mathrm{~cm}$.

\section{Unweighted and Woighted Averages}

If $x_{1} \pm \Delta x_{1}, x_{2} \pm \Delta x_{2}, \ldots . . x_{n} \pm \Delta x_{n}$ are $n$ independent measurements of a given quantity. $\Delta x_{1}$ being the uncertainty in $x_{1}$, then the weighted average of these measurements is $\vec{x} \pm \Delta \vec{x}$, where

$$
\begin{aligned}
& \bar{x}=w \sum x_{1} /\left(\Delta x_{1}\right)^{2} \\
& w=1 / \sum\left(\Delta x_{1}\right)^{-j}
\end{aligned}
$$

andi $\Delta \bar{x}$ is the lareer of

$$
\text { (w) })^{1 / 2}
$$

$$
\text { and }\left[W \Sigma\left(\Delta x_{1}\right)^{-2}\left(\bar{x}-x_{1}\right)^{2} /\left(x_{1}-1\right)\right]^{1 / 2} \text {. }
$$

The unweighted averace of these same measurements is given by $\bar{x} \pm \Delta \bar{x}$, where

$$
\begin{aligned}
& \bar{x}=\sum x_{1} / n, \\
& \Delta \bar{x}=\left[\sum\left(\bar{x}-x_{1}\right)^{2} / n(n-1)\right]^{1 / 2} .
\end{aligned}
$$




\section{Reforences}

47 Pri7 M. A. Preston - Phys. Rev. 71, 865 (1947); The Theory of Alpha-Radioactivity

$52 B 197$ J. M. Blett, V. F. Weisskopf - Theoretical Nuclear Physics, John Wiley and Sons, Inc., New York, p. 627 (1952)

58 Ro60 M. E. Rose - Internal Conversion Coefricienta, North-Hollend Publishing Co., Amsterdam (1958)

67 Be73 J. A. Bearden, A.F. Burr - Rev. Mod. Phys. 39, 125 (1867); Reevaluation of X-Ray Atomic Enercy Levels

$684 a 53$ R. S. Hager, E. C. Seltzer - Nucl. Data A4, 1 (1968); InternaJ Conversion Tabjes. Part I: K-, L-, $M-S h e l l$ Conversion Coerricients for $Z=30$ to $\mathrm{Z}=103$

6 6Ha54 S. Hager, E. C. Seltzer - Nucl. Data A4, 397 (1968); Internal Conversion Tables. Part II: Directional and Polarization Particle Parameters for $Z=30$ to $Z=103$

68Lo16 R. J. Lombard, C. F. Perdrisat, J. H. Brunner Nucl. Phys. A110, 41 (1968); Internal Pair Formation and Multipolarity of Nuclear Transitions

69Dro9 O. Dragoun, H. C. Pauli, F Schmutzler - Nucl. Data Tables A6, 235 (1969); Tables of Internal Conversion Coefficients for $\mathrm{N}-\mathrm{Subshell}$ Electrons

$69 H a 61$ R. S. Hager, E. C. Seltzer - Nucl. Data Tables A6, 1 (1969); Internal Conversion Tables. Part III: Coefficients for the Analysis of Penetration Efrects in Internal Conversion and EO Internal Conversion

70Kr03 K. S. Krane, R. M. Steffen - Phys. Rev. C2, 724 (1970); Determination of the $\mathrm{E} 2 / \mathrm{Mi}$ Multipole Mixine Ratios of the Gamma Transitions in $\mathrm{Cd}^{110}$

7 1Dr 11 O. Dragoun, Z. Plajner, F. Schmutzler - Nuct. Data Tables A9, 119 (1971); Contribution of Outer Atomic Shells to Total Internal Conversion Coefricients

71 Go40 N. B. Gove, M. J. Martin - Nucl. Data Tables A10, 205 (1971): Log-f Tables for Beta Decay
$715 t 47$ R. M. Steffen - Angular Distributions and Correlations of Radiation Emitted from Oriented Nuclei; Report LA-4565-MS, Los Alemos Scientiric Laboratory (197!)

715148 h. M. Steffen - Proc. InL Conf. Angular Correlations in Nuclear Disintezration, Delrt, Netherlands (1970), H. van Krugten, B. van Noojjen, Eds., Wolterst Noordhofr Publ., Groningen, p. 1 (1971); Angular Distributions and Correlations or Nuclear Radiations in Nuclear Spectroscopy

71 Ta 32 W. H. Taylor, B. Singh, F. S. Prato, R. MePherson Nucl. Data Tables AB, No. 1, 1 (1971): A Tabulation of Gamma-Gamma DirectionalCorrelation Coefricients

72An20 1. V. Anicin, R. B. Vukanovic, A. H. Kukoc - Nuc). Instrum. Methods 103, 385 (1972); The New Feature of 1-3 Directional Correlntions with Mixed Unobserved Transitions

72Bb16 W. Bambynek, B. Crasemann, R. W. Fink. H. U. Fruend, H. Mark, C. D. Swirt, R. E. Price. P. Venugopala Rao - Rev. Mod. Phys, 44, 716 (1972); X-Ray Fluorescence Yields, Auger. and Coster-Kronig Transition Probabilities

T2El21 Y. A. Ellis, M. R. Schmorak - Nucl. Dala Sheets B8. 345 (1972); Survey of Nuclear Structure Systematics for $A \geq 229$

$72 T r 09$ v. F. Trusov - Nucl. Data Tables 10, 477 (1972) Internal Conversion Coefficients for HighEnergy Transitions

76 Ba 63 I. M. Band, M. B. Trzhaskovskaya, M. A. Listengarten At. Nucl. Data Tables 18, 433 (1976); Internal Conversion Coefficients for Atomic Numbers Zs 30

$78 P 008$ F. T. Porter and M. S. Freedman J. Phys. Chem. Ref. Data 7, 1267 (1978) Recommended Atomic Electron Binding Energies, is to $6 p_{3 / 2}$. for Heavy Elements, $\mathrm{Z}=84$ to 103

79Ah01 1. Ahmad - Z. Phys, A290, 1 (1979) Precision Measurement of $\mathrm{K}$-Shell Fluorescence Yields in Actinide Elements 


\section{SUMMARY OF BASES FOR SPIN AND PARITY ASSIGNMBNTS}

\section{PROPOSITIONS ON WHICH STRONG ARGUMENTS ARB BASED}

\section{Ground States}

1. The ground state of an even-even nucleus has $\mathrm{J}^{\pi}=0^{+}$.

2. Spin determinations by such techniques as atomicbeam resonance, paramagnetic resonance, electron-spin resonance, and optical spectroscopy give correct values.

\section{Gamma Transitions}

3. The agreement of the measured value of single conversion coefficient with the theoretical value for a multipolarity which is well separated from the value for any other multipolarity determines the transition multipolarity.

4. In all other cases if there is no other evidence for multipolarity. agreement of two or more measured conversion coefficients or ratios with theoretical values is necessary in order to establish the multipolarities of a transition and its $\mathrm{m} / \mathrm{xine}$ ratio.

5. Since $E_{0}$ transition can proceed only by conversion or pair production. pure $E_{0}$ is ruled out if photons are observed.

6. Recommended upper limits for $\gamma$-ray strengths $\left(\Gamma_{\gamma} / \Gamma_{w}\right.$ $\Gamma_{v}$-Weisskopf eatimate) for various $A-v a l u e s$ are given below

\begin{tabular}{|c|c|c|c|}
\hline \multirow[b]{2}{*}{ Character } & \multicolumn{3}{|c|}{$\Gamma_{\gamma} / \Gamma_{Y}$ (Upper Limit) } \\
\hline & $A=6-44^{n t}$ & $A=45-150^{2.0}$ & $A>150^{\circ}$ \\
\hline E1 (IV) & $0.3^{\prime}$ & 0.01 & 0.01 \\
\hline E2 (IS) & 100 & 300 & 1000 \\
\hline E3 & 100 & 100 & 100 \\
\hline EA & 100 & $100^{\circ}$ & \\
\hline H1 (IV) & 10 & 3 & 2 \\
\hline IE (IV) & 3 & 1 & 1 \\
\hline M9 (IV) & 10 & 10 & 10 \\
\hline $\mathbf{4 4}$ & & 30 & 10 \\
\hline
\end{tabular}

- 'IV' and 'IS' stand for isovector and isoscalar I $\Gamma, \Gamma_{\text {w }}$ (Upper Limit)=30 for $A=90-150$

- $\Gamma_{\gamma} / \Gamma_{-}$(Upper Limit) $=0.1$ for $A=21-44$

- $r_{2} / \Gamma_{w}$ (Upper Limit) $=0.003$ for E1 (IS). 10 for E2 (IV), 0.03 for MI (IS), 0.1 for M2 (IS)

- From 79En04

- From 81En06

- Deduced from ENSDF by M. J. Martin

\section{Beta Trensitions}

7a. If $3.6<$ log $f t<5.9$, the transition is allowed: $\Delta \mathrm{J}=0$ or $1, \Delta \pi=+$ (no change in parity). For the mass region around $z=82$, the upper limit should be lowered to 5.1 .

$7 \mathrm{~b}$. If $3.0<\log f t<6.4$, the transition is not $0^{+} \rightarrow 0^{+}$. Superallowed $(\Delta T=0) 0^{+} \rightarrow 0^{*}$ transitions have log $f t$ in the rance 3.48 to 3.50 . Isospin forbidden $(\Delta T=1) 0^{*} \rightarrow 0^{*}$ transitions have loe $f t>6.4$.

8. If $\log f^{t u} t<8.5, \Delta \mathrm{J}=0,1 ; \Delta \pi= \pm$.

9. If los ft $<11.0, \Delta \mathrm{J}=0,1 ; \Delta \pi= \pm$ or $\Delta \mathrm{J}=2, \Delta \pi=-$.

10. If log $f t<12.8, \Delta J=0,1,2 ; \Delta \pi= \pm$.

11. If loe $f^{\text {tut }} \geq \mathbf{2 . 5 t}$ and if the Fermi plot has the curvature correspondine to shape factor $\left(p^{2}+q^{2}\right)$. then the transition is first-forbidden unique $(\Delta J=2, \Delta \pi=-)$.

See "B-Decay Rate Probabilities" on page App-D-iv. Note that $\left.\log f^{\prime u} t=\log f^{\prime} t+1.079\right)$.

- (10s $f e<7.4)$

$+(\log \mathrm{ft}+2.4)$

\section{rr Directional Correlation}

$$
W(\theta)=\sum_{k-k \operatorname{ken}} A_{k} P_{k}(\cos \theta) .
$$

12. If a temma-eamma directional-correlation experiment $y$ ields $A_{2} \approx+0.36$ nil $A_{4} \approx+1.1$, then the spin sequence is $0 \rightarrow 2 \rightarrow 0$.

13. Results of $\gamma \gamma(\cdot)$ are strong evidence for excluding spin sequences for which the theoretical $A_{2}$ or $A_{4}$ falls well outside the experimental range.

\section{Ar Directional Correlation}

$$
W(\theta)=\sum_{k-i v \in \mathbb{R}} A_{k}(\beta) A_{k}(\gamma) P_{k}(\cos \theta) .
$$

14. If $\left|A_{2}(\beta)\right| \geq 0.1\left(A_{4}=0\right)$, the transition is not allowed. The converse is not true.

15. If $A_{4}(\beta) \neq 0$. the transition is nejther allowed nor first-forbidden.

18 If $A_{4}(\beta)=0$, the tiansition is allowed or first-forbidden.

or Polarization Correlation

$$
P(\theta)=\frac{\sum_{k=\text { ddd }} A_{k}(\beta) A_{k}(\gamma) P_{k}(\cos \theta)}{W(\theta)}
$$

17. In allowed transitions,

$$
\begin{array}{ll}
\beta^{-} & A_{1}(\beta)<0 \text { if } \mathrm{J}_{1}=\mathrm{J}_{\mathrm{r}} \\
\beta^{+} & A_{1}(\beta)>0 \text { if } \mathrm{J}_{1}=\mathrm{J}_{\mathrm{r}} \\
\beta^{-} & A_{1}(\beta) \geq 0 \text { if } \mathrm{J}_{1}=\mathrm{J}_{\mathrm{r}}+1 \\
& A_{1}(\beta)<0 \text { if } \mathrm{J}_{1}=\mathrm{J}_{\mathrm{f}}-1 \\
\beta^{+} & A_{1}(\beta) \leq 0 \text { if } \mathrm{J}_{1}=\mathrm{J}_{\mathrm{p}}+1 \\
& A_{1}(\beta)>0 \text { if } \mathrm{J}_{1}=\mathrm{J}_{\mathrm{f}}-1
\end{array}
$$

18. If $A_{j}(\beta) \neq 0$, the $\beta$-transition is not allowed. The converse is not always true.

\section{Renctions}

19. Low-enerey Coulomb excitation is predominantly E2 excitation.

20. Coulomb excitation determines $\mathrm{J}^{\prime \prime}$ if the excitation probability aerees with the calculated values of Alder et al., Kel. Danske Videnskab. Selskab, Mat.-Fys. Medd. 32. No. 8 (1960).

21. The spin of the compound nuclear state resulting from thermal-neutron capture is equal to the spin of the taret nucleus plus or minus $h$.

22. Primary $\gamma$ 's from neutron capture are E1, M1, E2, or $\mathrm{MI}+\mathrm{E2}$.

23. If the angular distribution in a single-nucleon transfer reaction can be fitted with a unique $t$-value, the spin of the final state $J_{f}$ is related to the spin of the inital state $J_{i}$ by

$$
\vec{J}_{f}=\vec{J}_{1}+\vec{i}+\overrightarrow{\mathbf{i}}
$$

with parity change if $l$ is odd.

24 . For $\mathrm{Z}<50$ and $\mathrm{Z} \approx 82$, if the vector analyzine power for a single-nucleon transfer reaction shows a elear preference between $J=t+t / 2$ and $J=t-1 / 2$ and if the $t$-value is known, then the $J$-value is determined.

The limitation in the repions of applicablitty results from a lick of measurements in other rotions rather than an expected or observed violntion. 
SUMMARY OF BASES FOR SPIN AND PARITY ASSIGMBNTS - continuod

\section{PROPOSITIONS ON WHICH STRONG ARGUYENTS ARB BASBD continued}

25. If the angular distribution can be fitted with a unique $L$-value the $J^{*}$ of the rinal state is related to the $J^{*}$ of the initial state by $\vec{J}_{r}=\vec{J}_{1}+\overrightarrow{\mathrm{L}}, \pi_{r} \pi_{1}=(-1)^{2}$. for the rollowing cases

a. A strone group observed in $(p, t),(t, p)$, and $\left({ }^{3} \mathrm{He}, n\right)$ reactions (strong groups are assumed to result from two identical nucleons transferred in a relative s-state)

b. A strong eroup observed in the a-particle reaction ( $\left.{ }^{\circ} \mathrm{Li}, \mathrm{d}\right)$.

c. $\left(e, e^{\prime}\right)$ and $\left(\alpha, \alpha^{\prime}\right)$ inelastic scatering.

26. In reactions with $\mathrm{J}^{\pi}=0^{+}$target, projectle, and ejectile, if the yield of a group at $0^{\circ}$ or $180^{\circ}$ is

a. non-zero. the parity of the final state is $(-1)^{\text {sr }}$

b. zero at several uncorrelated enerejes, the parity of the rinal state is $(-1)^{\mathrm{d} r+1}$

In reactions with a polarized $J^{\pi}=1$ projectile in the $m=0$ substate. with $J^{n}=0^{*}$ ejectile and target, if the $y$ jeld of a group at $0^{\circ}$ or $180^{\circ}$ is

a. non-zero, the parity of the final state is $(-1)^{\text {dr+l }}$

b. zero at several uncorrelated energies, the parity of the rinal state is $(-1)^{\text {Jr }}$

\section{Macnetic Moments}

27. In nonrotational regions, if the know $n$ spin and magnetic moment of a level lead to an expected shell-model state by use of the Schmidt diagram. the level parity is determined.

28. In rotational regions, if the known spin and magnetic moment of a level agree with theoretical values for only one expected Nilsson level, the level parity is determined.

\section{Deformed Region - Band Structure}

Symbol

D Data from $\beta$ - or $\gamma$-transitions suegest $J^{\pi}=2^{+}$

$x$ The level is Coulomb excited

$y$ The level energy is given by the rotational level-energy formula

z,z' The inertial parameter, decoupling parameters, fits the local trend

In terms of the bove types of evidence. the followine rules can be stated for nuclet in the rotational regions. $00 \leq N \leq 112$, and $Z>87$.

29. For the rirst excited state in an even-even nucleus, $x$ or $D z$ is surficient to assign a spin and parity or $2^{+}$. 30. A level may be assigned to the ground-state rotational band on evidence of type $x z$ or $y z$, provided the ground-stale spin is well known.

31. A level may be assigned to a rotational band on evidence of type yz. provided at least one member of the band has well-known spin.

32. For $K=1 / 2$ bands, $y z^{\prime}$ is sufficient evidence to assign spins to the levels.

\section{Alpha Decay}

33. In odd-A nuclei, levels connected by $\alpha$-transitions have the same spin and parity if the hindrance factor is less than 4.

34. For $a$-decay between two states, one of which has $J=0$, the parity change is given by $\Delta \pi=(-1)^{\text {s. }}$.

\section{PROPOSITIONS ON WHICH WBAK ARGUMENTS ARB BASBD}

1. In cases where cammas of one multipolarity "cluster" in one time region in the half-life vs. energy plot, as is true for M4's, other $y$ 's whose half-lives fall in this cluster may be assizned the corresponding multipolarity.

2. In cases where cluster of two multipolarities occupy one time region e.z. M1 and E2, new eamma of which the half-life falls in this region may be assigned one of the two multipolarjics or a mixture o. the two.

3. Whenever $\triangle \mathrm{J} \geq 2$, an appreciable part of the eamma transition proceeds by the lowest possible multipole order.

This statement is based on the scarcity of counter-examples and the observation that few 82 r's are as slow is M3\%. Cow M2's as slow as E3's. etc.

4. Low-lying states of odd-A nuclel have shellmodel spins and parities except in the regions where deformations appear. This areument is much stronger when supported by expected cross-section strengths $\left(C^{2} S\right)$ in single-nucleon transfer reactions.

it is recosnized that some shell-model predictiona are stronger then others. Por exsmple, the shell model would mildly desy that the fround-atate $\mathrm{J}$ of the $39 \mathrm{th}$ proton be $3 / 2^{-}$. but emphatically deny its beine $3 / 2^{*}$. However. we heve not ineluded this distinction here and consider that all shell-model artuments are wesk.

5. The spin and parity of a parent state may be inferred from the measured properties of its assumed isobaric analog resonance, and vice versa.

6. In regions of nuclear deformation, the Nilsson model can be used to limit the possible spins and parities.

7. Stalements similar to 4 and 6 based on other models.

B. Statements based on interpolation or extrapolation of regional trends.

9. All stalements connected with the nonobservation of expected transitions.

\section{REPERENCES}

73Ra 10 S. Raman, N. B. Gove - Phys. Rev. C7, 1995 (1973); Rules for Spin and Parity Assignments Based on Loe $r t$ values

79Eno4 P. M. Endt, At.Data Nucl.Data Tables 23, 547 (1979); Strenglhs of Gamma-Ray Transitions in $A=45-90$ Nuclei

81En06 P. M. Endt, At.Data Nucl.Data Tables 26, 47 (1981); Strengths of Gamma-Ray Transitions in $A=$ 91-150 Nuclei 